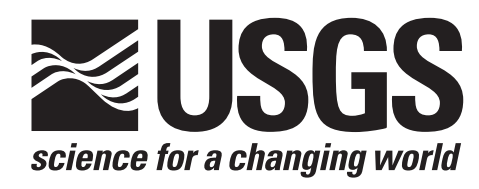

\title{
TRIGRS-A Fortran Program for Transient Rainfall Infiltration and Grid-Based Regional Slope-Stability Analysis
}

\author{
By Rex L. Baum ${ }^{1}$, William Z. Savage ${ }^{1}$ and Jonathan W. Godt ${ }^{1}$
}

Open-file Report 02-424

2002

This open-file report was prepared by an agency of the United States Government. Neither the United States Government nor any agency thereof nor any of their employees makes any warranty, expressed or implied, or assumes any legal liability or responsibility for the accuracy, completeness, or usefulness of any information, apparatus, product, or process disclosed in this report or represents that its use would not infringe privately owned rights. Reference therein to any specific commercial product, process, or service by trade name, trademark, manufacturer, or otherwise does not constitute or imply its endorsement, recommendation, or favoring by the United States Government or any agency thereof.

Although all data and software in this open-file report have been used by the USGS, no warranty, expressed or implied, is made by the USGS as to the accuracy of the data and related materials and (or) the functioning of the software. The act of distribution shall not constitute any such warranty, and no responsibility is assumed by the USGS in the use of these data, software, or related materials.

\section{U.S. DEPARTMENT OF THE INTERIOR \\ U.S. GEOLOGICAL SURVEY}

\footnotetext{
${ }^{1}$ Golden, Colorado
} 


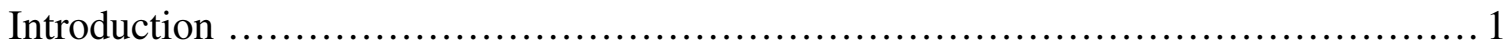

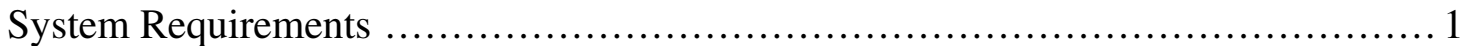

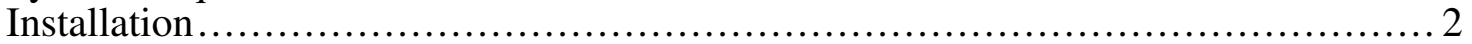

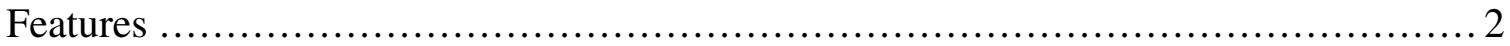

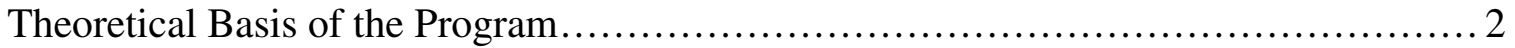

Infiltration models ............................................................... 3

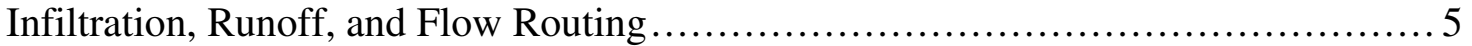

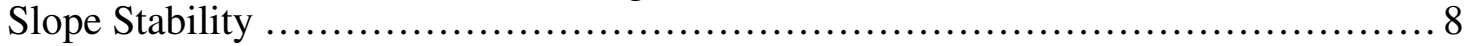

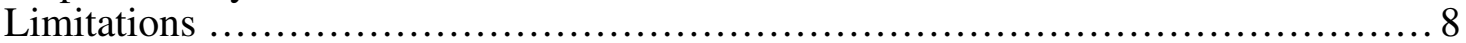

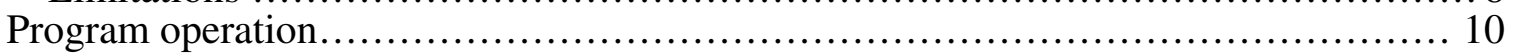

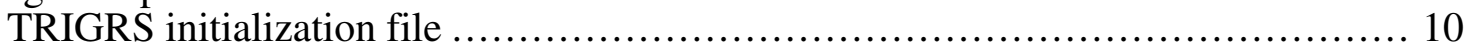

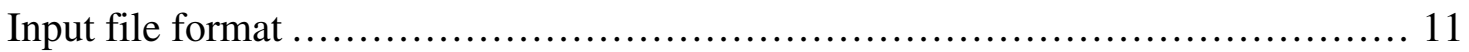

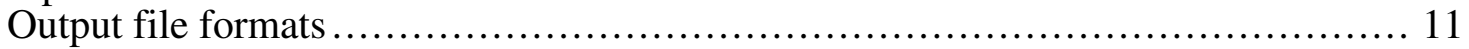

TopoIndex Initialization File................................................... 12

Troubleshooting ............................................................... 12

Comparison of computed results with published analyses.......................... 13

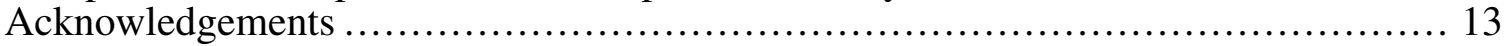

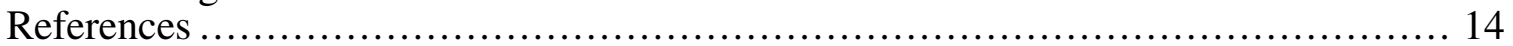

Appendix A. Listing of files included in this distribution............................ 29

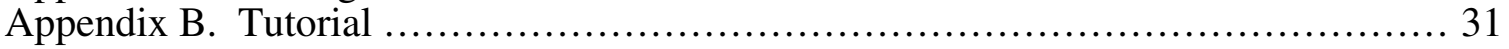

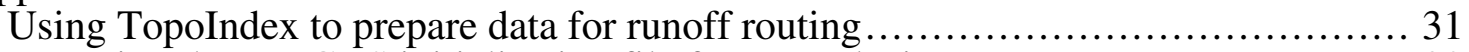

Preparing the TRIGRS initialization file for an analysis .......................... 32

Using TRIGRS to Analyze Slope Stability during a Simple Storm ...................... 34 


\section{Introduction}

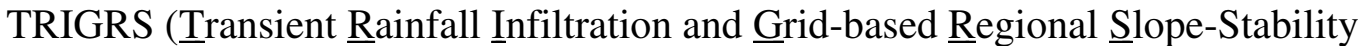
Model) is a Fortran program for computing transient pore-pressure changes, and attendant changes in the factor of safety, due to rainfall infiltration using the method outlined by Iverson (2000). We have extended Iverson's (2000) method by implementing the solution for complex storms, a solution for additional basal boundary conditions, and a simple runoff-routing scheme. The program operates on a gridded elevation model of a map area and accepts input from a series of ASCII text files. Infiltration, hydraulic properties, and slope stability input parameters are allowed to vary over the grid area thus making it possible to analyze complex storm sequences over geologically complex terrain. The optional routing scheme achieves mass balance between rainfall input, infiltration, and runoff over the entire grid by allowing excess water to flow to downslope cells that are receiving less direct precipitation than they are able to absorb. The program saves output to a series of text files that can be imported to GIS software for display or further analysis.

Analyses using TRIGRS are applicable to areas that are prone to shallow precipitation-induced landslides and that satisfy other model assumptions reasonably well. These assumptions include nearly saturated soil, a well-documented flow field and relatively isotropic, homogeneous hydrologic properties. The saturated soil assumption is approximately satisfied during the winter rainy season in parts of the U.S. Pacific coast region (Baum and others, 2002). Significant hydraulic heterogeneity may cause errors at boundaries between materials of differing hydraulic properties because TRIGRS uses infiltration models for a homogeneous, isotropic medium. However, we have not evaluated the magnitude of such possible errors. Model results are very sensitive to the initial conditions, particularly the steady component of the flow field and initial depth of the water table. Consequently, the model may produce questionable results where the initial water table depth is poorly constrained.

TRIGRS runs in a simple input/output window with relatively little user interaction. The user controls an analysis by means of an initialization file that contains the names of all other input and output files as well as other parameters needed to run the program. The following discussion will briefly describe system requirements for running the program, installation, features and limitations of the program, and provide a detailed description of the initialization file. A tutorial helps familiarize the user with program features and operation.

\section{System Requirements}

The program TRIGRS will run on computing platforms that support Fortran 77 and Fortran 90/95. The main program is written in standard Fortran 90 but uses Fortran 77 subroutines ${ }^{1}$. This distribution includes the source code and executable files that will run on Windows and Mac OS computers. The Windows version requires Windows 9x/NT/2000 and a Pentium-class processor. The program has not been tested with WindowsXP. The Mac OS version requires Mac OS 8.6 or later (including Mac OS X), CarbonLib 1.4 or later, and a PowerPC processor. The amount of RAM required depends on the problem size and the operating system. Analysis of a 24-period storm over a typical 30-m DEM for a USGS 7-1/2 minute quadrangle, which has about 175,000 cells, requires about $32 \mathrm{MB}$ of dedicated RAM (in addition to what is required by the operating

\footnotetext{
${ }^{1}$ Some of the subroutines make use of widely implemented, but non-standard, Fortran 77 extensions for string manipulation ("adjustl()") and type declaration ("implicit none").

${ }^{2}$ Portions of this program include material copyrighted ( $)$ by Absoft Corporation 1988-2002.
} 
system). Analysis of the same storm over a 10-m DEM (about 1,575,000 cells) requires about $284 \mathrm{MB}$ of dedicated RAM. The executable programs, source code, and documentation occupy about $9 \mathrm{MB}$ of disk space. Disk space for data storage requirements depend on the problem size.

\section{Installation}

The software can be downloaded from the U.S. Geological Survey publications web server at http://pubs.usgs.gov/of/2002/ofr-02-424/downloads/. After decompressing the archive file, copy the folder TRIGRS to any desired folder on your Windows PC, or Macintosh computer. Appendix A contains a listing of files included in this distribution. Appendix B gives a brief tutorial to acquaint the user with program operation.

\section{Features}

As mentioned previously, TRIGRS implements the method outlined by Iverson (2000) to compute transient pore pressure, due to vertical infiltration, and attendant changes in factor of safety in a digital landscape. We have extended Iverson's method by adding a solution for an impermeable basal boundary at a finite depth, and adding a simple runoff-routing scheme to disperse excess water from cells where the application rate (rainfall intensity) exceeds the infiltrability (infiltration capacity). The program allows the following input parameters to vary from cell to cell throughout the model: precipitation intensity, slope, soil depth, initial water-table depth, saturated vertical hydraulic conductivity, hydraulic diffusivity, cohesion for effective stress, angle of internal friction for effective stress, and total unit weight of soil. The precipitation rate may vary through time and may include water from other sources, if desired. By varying the time since the start of the storm during successive simulations, the user can observe the changes in the pore pressures and factors of safety as the storm progresses. The program reads ASCII grid files in a format that can be output by ArcView and Arc/Info. Program output is in the same ASCII grid format as the input except for an optional file that contains a listing of pore pressure and factor of safety at various depths for each grid cell. TRIGRS restricts the factor of safety to a maximum of 10 to facilitate plotting and eliminate division by zero in computing the factor of safety on flat slopes.

The main program was written in Fortran 90 to take advantage of its ability to allocate arrays dynamically. Consequently the executable can be used to analyze grids of various sizes and storms having an arbitrary number of periods of different rainfall intensity without the need to recompile the program. The upper limit of grid size that can be analyzed depends on compiler options, the operating system, and hardware being used. The interested user can find the source code in the TRIGRS folder.

\section{Theoretical Basis of the Program}

The application program TRIGRS combines models for infiltration and subsurface flow of storm water, routing of runoff, and slope stability to calculate the effects of storms on the stability of slopes over large areas. The following is a brief description of the basic models and formulas used by TRIGRS to represent these processes. Formulas used in TRIGRS refer to the coordinate system depicted in figures 1 and 2. 


\section{Infiltration models}

The ground-water flow field is modeled by superposition of a steady component and a transient component. The steady seepage component depends on the initial depth to the water table and a steady infiltration rate. The steady infiltration rate, the saturated hydraulic conductivity and the slope angle determine the steady (initial) flow direction. The vertical hydraulic gradient is a function of the slope, the initial (steady or background) infiltration rate and the saturated hydraulic conductivity. Model results are very sensitive to the steady-seepage initial condition. Consequently, accurate initial conditions are probably the most significant input for the model. Obtaining accurate initial conditions requires a significant number of field observations possibly supplemented by steady-flow modeling to extrapolate between observations. In the absence of accurate initial conditions, use of TRIGRS is limited to modeling hypothetical scenarios.

The infiltration models in TRIGRS are based on Iverson's (2000) linearized solution of Richard's Equation and our own extensions to that solution. His solution consists of a steady component and a transient component. The steady component allows flow in an arbitrary direction determined by the steady infiltration rate and the slope angle. The transient component assumes one-dimensional, vertical downward flow, with a simple specified time-varying flux of fixed duration and intensity at the ground surface and a zero flux condition for times greater than the starting time at an infinitely deep basal boundary (fig. 3). The infiltration models apply to saturated or tension-saturated initial conditions, so that flow is in the linear range for Darcy's law and the hydraulic diffusivity is approximately constant. We have generalized Iverson's (2000) original solution for the case of a time-varying sequence of surface fluxes of variable intensities and durations. The generalized solution used in TRIGRS is given by,

$$
\begin{aligned}
& \varphi(Z, t)=[Z-d] \beta \\
& +2 \sum_{n=1}^{N} \frac{I_{n Z}}{K_{Z}}\left[H\left(t-t_{n}\right)\left[D_{1}\left(t-t_{n}\right)\right]^{\frac{1}{2}} \operatorname{ierfc}\left[\frac{Z}{2\left[D_{1}\left(t-t_{n}\right)\right]^{\frac{1}{2}}}\right]\right] \\
& -2 \sum_{n=1}^{N} \frac{I_{n Z}}{K_{Z}}\left[H\left(t-t_{n+1}\right)\left[D_{1}\left(t-t_{n+1}\right)\right]^{\frac{1}{2}} \operatorname{ierfc}\left[\frac{Z}{2\left[D_{1}\left(t-t_{n+1}\right)\right]^{\frac{1}{2}}}\right]\right]
\end{aligned}
$$

In equation $1, \varphi$ is the ground-water pressure head, $t$ is time, $Z=z / \cos \alpha$, where $Z$ is the vertical coordinate direction, $z$ is the slope-normal coordinate direction, and $\alpha$ is the slope angle (fig. 1 and 2); $d$ is the steady-state depth of the water table measured in the $z$ direction, $\beta=\lambda \cos \alpha$, where $\lambda=\cos \alpha-\left[I_{Z} / K_{Z}\right]_{L T}, K_{Z}$ is the hydraulic conductivity in the $\mathrm{Z}$ direction, $I_{Z}$ is the steady (initial) surface flux, and $I_{n Z}$ is the surface flux of a given intensity for the $n^{\text {th }}$ time interval. The subscript $L T$ denotes long term, $D_{1}=D_{0} \cos ^{2} \alpha$, where $D_{0}$ is the saturated hydraulic diffusivity, $N$ is the total number of intervals, and $H\left(t-t_{n}\right)$ is the Heavyside step function. The first term in equation 1 represents the steady part of the solution and the remaining terms represent the transient part. Figure 4 
illustrates the kind of storm history that equation 1 is capable of modeling. The function ierfc is of the form

$\operatorname{ierfc}(\eta)=\frac{1}{\sqrt{\pi}} \exp \left(-\eta^{2}\right)-\eta \operatorname{erfc}(\eta)$

and $\operatorname{erfc}(\eta)$ is the complementary error function.

As an alternative to the solution with an infinite basal boundary, we have added and implemented in TRIGRS a solution for pore pressure in the case of an impermeable basal boundary at a finite depth (fig. 3). This solution is given by,

$$
\begin{aligned}
& \varphi(Z, t)=[Z-d] \beta \\
& +2 \sum_{n=1}^{N} \frac{I_{n Z}}{K_{Z}} H\left(t-t_{n}\right)\left[D_{1}\left(t-t_{n}\right)\right]^{\frac{1}{2}} \sum_{m=1}^{\infty}\left\{\operatorname{ierfc}\left[\frac{(2 m-1) d_{L Z}-\left(d_{L Z}-Z\right)}{2\left[D_{1}\left(t-t_{n}\right)\right]^{\frac{1}{2}}}\right]+i e r f c\left[\frac{(2 m-1) d_{L Z}+\left(d_{L Z}-Z\right)}{2\left[D_{1}\left(t-t_{n}\right)\right]^{\frac{1}{2}}}\right]\right\} \\
& -2 \sum_{n=1}^{N} \frac{I_{n Z}}{K_{Z}} H\left(t-t_{n+1}\right)\left[D_{1}\left(t-t_{n+1}\right)\right]^{\frac{1}{2}} \sum_{m=1}^{\infty}\left\{\operatorname{ierfc}\left[\frac{(2 m-1) d_{L Z}-\left(d_{L Z}-Z\right)}{2\left[D_{1}\left(t-t_{n+1}\right)\right]^{\frac{1}{2}}}\right]+i \operatorname{ierfc}\left[\frac{(2 m-1) d_{L Z}+\left(d_{L Z}-Z\right)}{2\left[D_{1}\left(t-t_{n+1}\right)\right]^{\frac{1}{2}}}\right]\right\}
\end{aligned}
$$

Except for the addition of $d_{L Z}$, the depth of the impermeable basal boundary measured in the $Z$-direction, the notation in equation 2 is the same as that in equation 1 . The infinite series in equations 1 and 2 converge rapidly so that in computation, only the first few terms of the series are needed.

Equations 1 and 2 represent two different subsurface conditions (fig. 3). Equation 1 applies where hydraulic properties are uniform with depth and equation 2 applies where a well-defined decrease in hydraulic conductivity exists at a finite depth. For example, equation 2 would apply where loose relatively permeable slope deposits overlie relatively impermeable bedrock. We considered allowing the user to specify a flux at the basal boundary; however, this would add another unknown to the problem without adding significantly to the program's analytical capabilities. Equations 1 and 2 can be viewed as end members of the specified-flux basal boundary condition. Note that only one end member (either equation 1 or 2) is applied to all cells in an analysis.

Following Iverson (2000) we impose an additional physical limitation that pressure head under downward gravity-driven flow cannot exceed that which would result from the having the water table at the ground surface, that is,

$\varphi(Z, t) \leq Z \beta$ 
Thus, TRIGRS automatically reduces pressure head to $Z \beta$ anywhere that equation 1 or 2 has computed a value that is higher than $Z \beta$.

TRIGRS applies a modified form of equation $3 \mathrm{a}$ at cells where the initial flow direction is upward. If the steady water table is at the ground surface, then exfiltration occurs and any precipitation runs off along with the exfiltrating water. If the initial water table is below the ground surface and flow is upward, then TRIGRS allows precipitation to infiltrate until it raises the water table to the ground surface. This is accomplished by adding the transient and initial pressures above the water table as at other cells by applying either equation 1 or 2 and maintaining the steady upward hydraulic gradient below the water table as indicated in figure 5. The following formula applies below the water table in such cells.

$\varphi(Z, t)=\left(Z-d_{t}\right) \beta ; Z>d_{t}$

In equation $3 \mathrm{~b}, d_{t}$ is the depth to the transient water table.

Both equations 1 and 2 are generalizations of analogous heat-flow problems (Carslaw and Jaeger, 1959). Equations 1 and 2 are valid for saturated and nearly saturated soils for which the infiltrability and hydraulic conductivity approximately equal the saturated hydraulic conductivity. The solutions are strictly valid only where transient infiltration is vertically downward; however, in application, computed pore pressures will likely be accurate enough if the transient lateral flow component is relatively small. However, the steady-flow component may have any direction consistent with possible values of $\beta$; consequently, superposition of the transient and steady components can result in flow in an arbitrary direction. As a result of approximations made in linearizing Richard's equation, the formulas are valid for homogeneous soils and for depths that are shallow compared to the square root of the upslope contributing area (Iverson, 2000). TRIGRS allows the hydraulic conductivity and diffusivity to vary from cell to cell, however the user should be aware that this violates the model assumption of homogeneity, and may lead to inaccurate results near boundaries between units that have different hydraulic properties.

The formulas for both solutions of the infiltration model (equations 1 and 2) include the complementary error function. The program, TRIGRS, uses an approximation of the error function that was developed by W.J. Cody of Argonne National Laboratory (Cody, 1969). The original Fortran source code, also by W.J. Cody, is archived online at http://www.netlib.org/specfun/erf.

\section{Infiltration, Runoff, and Flow Routing}

The program, TRIGRS, uses a simple method for routing of surface runoff from cells that have excess surface water to adjacent downslope cells where it can either infiltrate or flow farther downslope ${ }^{3}$. We assume that runoff occurs when the precipitation and runoff

\footnotetext{
${ }^{3}$ Runoff routing is applied only to the transient part of the solution. If TRIGRS detects that the steady infiltration rate at a cell exceeds the saturated hydraulic conductivity, it reduces the value of $I_{s} / K_{s}$ to a value that makes $\beta=0$ at the cell, with the result that pressure head above the user-specified steady water table is zero. Cells where this occurs are identified in the log file, so that the user can go back and correct the input data.
} 
supplied to a cell exceed its infiltrability. The saturated hydraulic conductivity, $K_{s}$, generally equals the infiltrability, $i$, for saturated and tension-saturated soils (Hillel, 1982; Iverson, 2000). The purpose of routing the surface runoff is to prevent the loss of excess precipitation that cannot infiltrate at its cell of origin and to improve the performance of the model in urbanized or other areas where pavement or other impervious surfaces exist. However, the user may bypass the runoff routing, if desired. Running TRIGRS without routing would be appropriate where a complex system of storm drains complicates runoff routing.

We compute the infiltration, $I$, at each cell as the sum of the precipitation, $P$, plus any runoff from upslope cells, $R_{u}$, with the limitation that infiltration cannot exceed the saturated hydraulic conductivity, $K_{s}$.

$I=P+R_{u} ; I \leq K_{s}$

At each cell where $P+R_{u}$ exceeds $K_{s}$ the excess is considered runoff, $R_{d}$ and is diverted to adjacent downslope cells.

$R_{d}=P+R_{u}-K_{s} ; R_{d} \geq 0$

Overland flow between adjacent cells is assumed to occur instantaneously, we have made no attempts to model the rate of overland flow. Consequently, individual storm periods should be long enough to allow surface water to flow to adjacent cells. The routing method enforces mass balance for each time step through the storm; the total precipitation at all the cells must equal the water that infiltrates at all the cells, and the water that flows to edges of the problem domain (or any closed depressions) without infiltrating. Thus, excess precipitation that cannot infiltrate at its cell of origin has the opportunity to infiltrate at some point downslope. However, TRIGRS does not carry runoff over from one time step to the next, nor does it track water that enters storm drains. In other words, water that runs off a cell during any given time step must either infiltrate at another cell or reach the edge of the model (or some other sink) within that time step.

In addition to runoff from cells where precipitation exceeds the infiltrability, water is assumed to run off from any cells where the water table is initially at the ground surface and the initial (steady) rate of infiltration is negative. Water is exfiltrating from such cells and runs to the adjacent downslope cell(s). TRIGRS tracks exfiltrating water in the mass balance calculations.

By computing the infiltration and runoff at cells in order from the topographically highest cell(s) to the lowest, the program TRIGRS avoids the necessity of iterating to reach a solution that satisfies mass balance. Mass-balance calculations for each storm time step verify that all water applied as input is accounted for as either infiltration or runoff. Mass balance will be achieved only if the topographic data have been correctly indexed. A digital elevation model (DEM) can be indexed correctly only if it has been adjusted in GIS software to be hydrologically consistent. TRIGRS writes the results of the mass-balance calculations to a log file, named "TrigrsLog.txt", in the same folder as the application. 
A companion utility program TopoIndex (Topographic Index), which is included in this distribution, prepares a group of data files for the runoff-routing calculations. These files contain a list of cell numbers ranked in order from highest to lowest elevation, and a grid of cell numbers indicating the neighboring cell on the steepest downslope path. TRIGRS uses these data to control the order of runoff routing calculations as described above. If any of these files are missing, then TRIGRS will compute infiltration based on the rainfall input without routing any excess surface water. The output files of TopoIndex also contain a list of grid cells and their downslope neighbors, along with a list of weighting factors that determine what proportion of the runoff is transferred to each neighboring downslope cell.

The program TopoIndex uses a two-step process to index the cells from highest to lowest elevation. The first step consists of defining an index based on the "Heapsort" algorithm for sorting the cell elevations (Press and others, 1986). The second step corrects the index by comparing the indices of neighboring cells to their relative positions along downslope paths. If the indices of two neighboring cells that have the same apparent elevation (due to numerical rounding or truncation) are out of order, they are swapped. The second step is repeated by passing through the grid for a specified number of iterations or until the number of corrections on the last pass equals zero. We have successfully tested TopoIndex on a grid of approximately 2 million cells. TRIGRS uses output files from TopoIndex to implement the runoff-routing scheme described in the previous paragraphs. Our tutorial (Appendix B of this report) describes how to operate the utility program and prepare data for the analysis. Figure 6 shows the designation of D8 flow directions used by TopoIndex. Successful operation of TopoIndex requires the use of a hydrologically consistent DEM as input. TopoIndex does not account for storm drains and similar artificial drainage diversions that are not expressed in the topography.

TopoIndex allows the user considerable latitude in determining how excess water, $R_{d}$, will be distributed among the downslope cells. Table 1 outlines the available choices of distribution patterns, which (in this implementation) apply only to square cells. Many of the patterns depend on an exponent, $\omega$, and the slopes between the current grid cell and its downslope neighbor cells similar to the method of Freeman (1991). The same exponent is used in computing weighting factors throughout the grid. The default case $(\omega>20)$ is to divert excess water only to the adjacent cell on the steepest downslope path (the D8 method of O'Callaghan and Mark, 1984). Letting $\omega=0$ distributes the excess water evenly among all adjacent downslope cells; this pattern has the greatest dispersion of all the choices. If $\omega=1$, then flow is distributed among all downslope cells in proportion to the slope, which is equivalent to the method of Quinn and others (1991). Tarboton (1997) showed that this method has significant dispersion. Choosing higher exponents decreases the dispersion and diverts increasing proportions of the flow to the cell on the steepest downslope (D8) path. Negative exponents are not implemented because they would concentrate flow on flatter slopes.

If the user enters a negative exponent in the TopoIndex initialization file, it acts as a flag to select a method that is similar to Tarboton's (1997) $D \infty$ method. The $D \infty$ method assumes that water flows down the steepest slope, computes the direction of steepest slope and attempts to direct flow in that direction by partitioning the flow between the two cells nearest to the steepest slope direction. In this case, TopoIndex uses the D8 direction as a starting point and compares the slopes of the two neighboring directions to identify the triangular facet that contains the steepest slope. If the steepest slope coincides with the D8 flow direction, then all flow is diverted to the cell in that direction. Otherwise flow is distributed between the two cells that straddle the direction of the steepest slope; the weighing factors are proportional to the angles between the grid directions and the dip direction of the facet as described by Tarboton (1997). 
Each of the runoff distribution patterns has its peculiar advantages and disadvantages. The D8 method is the simplest, and has the lowest dispersion; however, the resulting runoff distribution is irregular and somewhat unrealistic. We prefer the $\mathrm{D} \infty$ method because it is physically more realistic than any of the other methods implemented in TopoIndex. The D $\infty$ method is used in SINMAP (Pack and others, 1998). The remaining methods, in which the weighting factors are proportional to the slope raised to an exponent, are provided to allow the user to achieve greater dispersion or smoothing of the runoff distribution, if desired.

\section{Slope Stability}

Following Iverson (2000), we model slope stability using an infinite-slope stability analysis. In his analysis, failure of an infinite slope is characterized by the ratio of resisting basal Coulomb friction to gravitationally induced downslope basal driving stress. This ratio, called the factor of safety, $F_{S}$, is calculated at a depth $Z$ by

$$
F_{S}=\frac{\tan \phi}{\tan \alpha}+\frac{c-\varphi(Z, t) \gamma_{W} \tan \phi}{\gamma_{S} Z \sin \alpha \cos \alpha}
$$

where $c$ is soil cohesion, $\phi$ is the soil friction angle, $\gamma_{w}$ is unit weight of groundwater, and $\gamma_{S}$ is soil unit weight. The pressure head in equation 6 is subject to the limitation imposed by equation 3 and is obtained from either equation 1 or 2 depending on the assumption regarding the type of basal boundary.

Factors of safety, $F_{S}$, are calculated by equation 6 for transient pressure heads at multiple depths $Z$ (fig. 7). Failure is predicted when, $F_{S}=1$, and stability holds where $F_{S}>$ 1. Thus the depth $Z$ where $F_{S}$ first reaches 1 will be the depth of landslide initiation. This initiation depth will vary with the time and depth variation of pressure head that, in turn, depends on rainfall history.

\section{Limitations}

All numerical and analytical models of ground-water flow and slope stability are subject to limitations imposed by simplifying assumptions and other shortcomings in the underlying theories. TRIGRS is based on a transient vertical infiltration model combined with a simple slope stability model derived by Iverson (2000) and is subject to the same limitations that are inherent in the original model:

- The model assumes flow in saturated or nearly saturated homogeneous, isotropic soil; thus it cannot be applied to areas with dry initial conditions and anisotropy or heterogeneity may cause errors in the solution. The assumption of near-surface soils being saturated or nearly saturated so that they are in the linear range of Darcy's law is consistent with field observations at sites in Hawaii and Oregon (Baum and Reid, 1995; Torres and others, 1998). This assumption may be fairly well satisfied in finegrained soils during well-defined wet seasons such as those that occur during the winter on the U.S. Pacific coast. 
- The results are very sensitive to the initial conditions. Ideally, the user should know the initial water table depth and something about the initial flow field throughout the study area. The user must specify the initial depth of the water table and steady infiltration or exfiltration rate at each cell or estimated values for the entire area. The initial water-table depth and rate allow the user to represent fairly general initial flow conditions. In urban and suburban areas, data from geotechnical borings and monitoring wells for environmental remediation projects may provide estimates of the initial conditions. In the absence of detailed information, simple ground-water flow models that can be adapted to hillslope conditions might provide reasonable estimates.

- The program uses a simple method for routing surface runoff from cells where precipitation exceeds the infiltrability ( $K_{s}$ for saturated and tension-saturated soils) to neighboring downslope cells. This method does not account for evapotranspiration, which is expected to be low during most storms. Furthermore, the runoff routing model cannot be used to estimate stream flow, because runoff from cell to cell is assumed to happen instantaneously and the runoff receives no contributions from subsurface flow, except cells where steady exfiltration is specified in the initial conditions.

- Procedures for correcting and preprocessing digital elevation models (filling pit artifacts or one-cell depressions, and computing flow directions) are not included in TRIGRS or TopoIndex. However, such procedures are available in modern GIS software. TopoIndex and TRIGRS require a DEM that has been corrected to remove noise, such as one-cell depressions.

- Model results are sensitive to the engineering properties of geologic units in the model area, some of which may vary over orders of magnitude. For any geologic material the hydraulic conductivity and diffusivity may vary over several orders of magnitude.

- The slope-stability model is based on an infinite slope analysis, which assumes uniform slope, thickness, physical properties, and that pore-water pressure is only a function of depth and time. Applying this method over a grid that represents threedimensional topography may result in errors where slope, thickness, physical properties or pore pressure changes abruptly. Non-uniform lateral stresses (or intercell forces) and non-planar failures may occur in areas where the infinite slope assumptions are violated. Thus, the model is more accurate where conditions favor planar failure, which typically occur at depths that are shallow compared to the width of the grid cells and in areas where slopes have a relatively uniform mantle of weathered material. Based on published comparisons of various methods of slope stability analysis, we expect the model to compute lower factors of safety than more rigorous methods of stability analysis would in areas where failures tend to be nonplanar (Duncan, 1996).

- The program does not check for consistent units of measurement between the different input parameters. However, we have provided a simple utility program called UnitConvert that can be used to convert data contained in grid files between different systems of units.

- Lack of information about how conditions change once a slope has failed limits the ability of TRIGRS to forecast what happens after the factor of safety has fallen below unity (failure) at any particular grid cell. Although it is feasible to modify TRIGRS to update the properties and hillslope geometry after failure occurs, the main difficulty 
lies in predicting what the updated properties and geometry should be. In many instances, the scars of shallow failures expose more competent material and considerable time (years to decades) must pass before sufficient weathered material accumulates to allow failure at the same location. However, depending on cell size, successive failures might occur at neighboring locations within the same cell during a storm. Consequently, for computational purposes, we have treated cells as if they are unchanged by failures during a given simulation.

\section{Program operation}

The programs TRIGRS, TopoIndex, and UnitConvert are launched like any other Windows or Mac OS application, by double clicking their icons. Upon starting, TRIGRS opens a user-supplied initialization file, and reads a list of file names and parameters needed to compute the pore pressures and factors of safety in each cell. The program then opens and reads files of input data, computes the results and saves the output to a series of files. The program then exits automatically when it is finished. TRIGRS writes a brief log file that may be useful in troubleshooting or in keeping a record of successive analyses. The log file includes a record of the starting and ending time, any errors that occurred, and a copy of data from the initialization file. TopoIndex and UnitConvert both operate in the same manner. Successful operation of the programs depends on understanding how to edit their initialization files and the proper format of the input files. Therefore, we describe the format and contents of these files before presenting a brief tutorial (Appendix B).

Each time TRIGRS runs, it analyzes the data for a single specified elapsed time in the storm sequence. To observe how pore pressures and factors of safety change during a storm, it is necessary to run TRIGRS for different values of elapsed time, $t$.

\section{TRIGRS initialization file}

The initialization file controls input and output. Use of an initialization file accelerates analysis when compared to repeatedly choosing input files from interactive dialog boxes. The initialization file is in ASCII text format and contains a list of input file names and constants needed to complete the analysis. To change problem parameters, the user edits the initialization file using a text editor. Consequently, most runtime errors result from mistakes in editing the initialization file or errors in the input grids. A descriptive or explanatory heading precedes each line (or in one case a group of related lines) of data in the initialization file to reduce errors in editing the file. The first few lines contain a project title followed by numeric data, the next group of lines contains names of input files and the final group of lines specifies which output files will be saved. Table 2 shows the organization of the initialization file and defines the input file names using partial path names (starting at the current folder). The next few paragraphs describe the structure of the initialization file and general characteristics of the data. We have provided a more detailed explanation of the initialization data needed to perform a simulation in the tutorial.

Numeric data. -- The file contains five lines of numeric data needed to determine array sizes, precipitation history, initial conditions, and physical properties. The user may set physical parameters, except slope, to a constant value over the entire grid by specifying a positive value. A negative value of a parameter prompts the program to read an input grid for spatially variable data. Table 3 defines the numeric variables listed in table 2 and indicates appropriate ranges of values. Table 2 is an example listing of the initialization file. 
Input files. -- The user must specify a file name for each input file. TRIGRS automatically reads a name for each potential input file; therefore the user must provide a placeholder for any input file for that either does not exist or will not be used for a given simulation. TRIGRS can accept either full or partial path names ${ }^{4}$ as long as 255 characters; however the rules for specifying path names vary between operating systems. If the paths are typed incorrectly, the program will report an error. To minimize errors in specifying file path names, the user may place all the input data files needed for a given simulation into a specific folder and a copy of the program file and initialization file into the folder where the data reside. By doing so, the user needs only to specify the file names and does not need to worry about the paths.

Output files. -- Table 4 lists the names and describes the contents of the output files that TRIGRS can generate. A series of seven logical values (true or false) determines which output grid files are saved to disk. A numeric flag on the last line of the input file determines whether the cell by cell list file is saved and whether it contains optional data. The user may specify an identification code to group files from a particular simulation. Users may also specify a folder where the output files can be saved.

On start-up, TRIGRS will look for the default initialization file, "trigrs.ini" in the same folder as the program file resides. If it is not present, then TRIGRS prompts the user to enter the name of the initialization file. TopoIndex and UnitConvert follow a similar convention.

\section{Input file format}

Most input files contain gridded data and all grid files use the same basic format, consisting of a short list of file parameters followed by the grid data. The files are in space-delimited ASCII text format (identified by the ".asc" file suffix) and can be viewed or edited with a text editor. The first six lines of the file list a file parameter preceded by a text label up to 14 characters long (table 5). The grid data begins at the upper left-hand corner cell and the cells are listed from left to right, and row by row from top to bottom. The grid data may be written in either decimal or scientific floating-point format. Spaces, commas, or tabs may be used as delimiters. The default "no data" value for cells to be

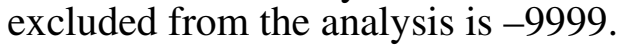

The only exceptions to the grid-file format are files used to control the routing of excess water. These text files include three lists as shown in tables 6,7 , and 8. Table 6 illustrates the format of a file containing a list of cells downslope from each grid cell. Table 7 follows a similar format and contains the weighting factors for the corresponding cells listed in table 6 . Table 8 illustrates the format of the index file that indicates the order in which cells are analyzed to correctly partition infiltration and runoff. The input routing method also uses a grid file that indicates which neighboring cell is on the steepest downslope path.

\section{Output file formats}

TRIGRS automatically generates a log file and can generate optional output files (if specified in the initialization file, table 2). The log file (always named "TrigrsLog.txt") contains information about program operation and repeats the data from the initialization file. By renaming the file, (add the identification code applied to the other output files from the simulation) the user can save a record of the simulation to keep with the other

\footnotetext{
${ }^{4}$ The full path is the concatenation of the drive name, the folder name(s) and the file name. For example, C:IVProgram FilesITRIGRSITRIGRS.EXE is a full path name and TRIGRSITRIGRS.EXE is a partial path name. Parent directories can be specified by typing "..." in Windows or "::" in the Mac OS.
} 
output files. Most of the optional output files follow the same grid format as the input files. Two of the files contain the pore pressure and factor of safety at the maximum depth, zmax, and three others contain (1) the minimum factor of safety, (2) the pressure head, and (3) the depth at which the minimum occurs. In case of runoff, TRIGRS saves a file showing runoff at the end of each storm period.

Another optional output file contains a cell-by-cell listing of the pore pressure and factor of safety at each depth in the profile (fig. 7 and table 9). This file can easily become quite large because its size increases with the user-specified number of vertical increments (fig. 7) and with the number of cells in the grid. For example, on a grid with 20,522 cells, the profile data using five vertical increments (six points per cell) occupied about $5 \mathrm{MB}$, where the ASCII grid output files occupied $368 \mathrm{~KB}$ each.

\section{Topolndex Initialization File}

TopoIndex requires less input than TRIGRS, but its initialization file is similar in design. Table $10 A$ shows an example initialization file for TopoIndex. The first two lines contain numeric data needed to control program operation and establish array sizes. The next two contain the names of input files and the remaining lines control output. Table $10 B$ lists the output files. TRIGRS uses four of the seven output files that TopoIndex is capable of generating. The other three are provided as a convenience for the user in visualizing the data.

\section{Troubleshooting}

The program displays the message "Cannot locate default initialization file, type name of initialization file and press RETURN to continue." TRIGRS and the associated utility programs expect the initialization file to be in the same folder as the program file. If the file has been moved, renamed, or left open by a text editor or other application, then TRIGRS will not be able to open it. After the user types the name of the initialization file, TRIGRS will attempt to open it. If TRIGRS opens the file, it will proceed; otherwise, TRIGRS will quit.

TopoIndex does not converge--If the topographic indexing corrections do not converge after a specified number of iterations, then TopoIndex will terminate without generating most of the expected output files. The log file of "TopoIndexLog.txt" will generally show the corrections converging rapidly during the first several iterations and then stuck at a constant number of corrections during the remaining iterations until the program terminated. This usually results from using a DEM that has not been hydrologically corrected by filling single-cell depressions. Such corrections should be done in GIS software before generating the flow direction grid. Genuine depressions such as lakes may be included in the analysis if adequate bathymetric data exist or they can be excluded from the analysis by designating such areas as no data cells in all grids.

TRIGRS displays an error message referencing a file name--This usually results from errors in opening, reading or writing to a file. Errors opening files may result from incorrect path or file names. Check the path name of the file as entered in the initialization file to be sure it is typed correctly. Errors writing to an output file may result from selecting a file that is locked, already open, or trying to write to a folder that does not exist. Check to be sure that the file is not open in another application.

TRIGRS displays an error message referencing a program line number--This may result from errors in reading or writing a file. Open the corresponding file, correct any errors and try again. Array boundary errors can result from entering incorrect values in the initialization file (tables 2, 3, and 4) or from listing input or output files in the wrong 
order. Such errors may also result if some of the input grids are incompatible (do not match) with each other as described in the next paragraph.

The arrangement of cells in the output grids does not match that in the original DEM-This usually indicates that one or more of the input grid files is incompatible with the others. Such incompatibility may result from differences in boundaries used to assign properties or to define no-data cells. For example, if using geologic map coverage to generate grids of physical properties and applying a shoreline from a different coverage to define no-data cells in the elevation grid, a mismatch may occur along the shoreline. In other words, one grid may contain no-data cells at the same (row-column) locations as data cells in the other grid. All grids for a study area must have the same number of rows and columns, and the same number of no-data cells in the same locations so that grid cell numbers will agree between grids (fig. 8). This is critical because TRIGRS uses onedimensional arrays to store the grids, which saves memory and accelerates computations when analyzing grids that have significant numbers of no-data cells. Therefore when preparing grids for analysis, it is necessary when applying boundaries to GIS layers to apply them consistently. The TRIGRS log file lists the number of data cells from each grid file to aid in identifying grid mismatch.

A program displays the message: "\# Buffer allocation failed". Users of Mac OS 8.6 or 9 will see this message if the program needs more memory. Increase the program's memory allocation ${ }^{5}$ and relaunch the program.

\section{Comparison of computed results with published analyses}

We tested TRIGRS against Iverson's (2000) examples from the Minor Creek landslide and an experiment at the USGS debris-flow flume and were able to reproduce the pore pressure and factor of safety profiles he computed. Thus, we were able to verify that the computer code accurately implements Iverson's (2000) formulas for pore pressure and factor of safety. Folders named "MinorCreek" and "flume" contain files with necessary data to reproduce these results. By varying elapsed time, $t$, in the initialization file, the user can compute pressure head and factor of safety profiles like those of figures 7, 8, and 10, and 11 of Iverson (2000). Note that the computed profiles conform to the limit imposed by equation 3 .

\section{Acknowledgements}

Mark Reid and Jon McKenna (both USGS) provided critical reviews of the program and documentation. John Michael (USGS) prepared GIS grids used in development and testing of the programs. Bill Schulz (USGS) tested the tutorial and software and provided helpful suggestions.

\footnotetext{
${ }^{5}$ Press the Return key to quit the program. In the Finder select the program icon and choose "Get Info" from the "File" menu. Select Memory from the pop-up menu in the Info window, and type a larger number in the "Preferred Size" field. Then close the Info window. The Excel spreadsheet "memoryReq.xls" included in the TRIGRS folder can be used to estimate the amount of memory needed by the program.
} 


\section{References}

Baum, R.L., Harp, E.L., McKenna, J.P., McMullen, S.R., Kibler, J.D., and Barnett, Elizabeth, 2002, Application of near-real-time monitoring to study of coastal bluff instability, Snohomish County, Washington: Geological Society of America Cordilleran Section Meeting, May 13-15, Abstracts with Programs, v. 34, no. 5 p. A-23.

Baum, R.L., and Reid, M.E., 1995, Geology, hydrology, and mechanics of a slowmoving, clay-rich landslide, Honolulu, Hawaii: GSA Reviews in Engineering Geology X, p. 79-105.

Carslaw, H.S., and Jaeger, J.C., 1959, Conduction of Heat in Solids: New York Oxford University Press, 510 p.

Cody, W.J., 1969, Rational Chebyshev approximations for the error function: Math. Comp., p. 631-638.

Duncan, J.M., 1996, Soil slope stability analysis, in Turner, A.K., and Schuster, R.L., Landslides--Investigation and Mitigation: Transportation Research Board Special Report 247, Washington, D.C., National Academy Press, p. 337-371.

Freeman, T.G., 1991, Calculating catchment area with divergent flow based on a regular grid: Computers and Geosciences. v. 17, no. 3, p. 413-422.

Freeze, R.A., and Cherry, J.A., 1979, Groundwater, Englewood Cliffs, New Jersey, Prentice Hall, 604 p.

Hillel, Daniel, 1982, Introduction to soil physics: Academic Press, San Diego, 364 p.

Iverson, R.M., 2000, Landslide triggering by rain infiltration: Water Resources Research, v. 36, no. 7, p. 1897-1910.

O'Callaghan, J.F. and Mark, D.M., 1984, The extraction of drainage networks from digital elevation data: Computer Vision, Graphics and Image Processing, v. 28, p. 328-344.

Pack, R. T., Tarboton, D. G., and Goodwin, C. N., 1998, The SINMAP approach to terrain stability mapping, in International Congress of the International Association of Engineering Geology and the Environment, $8^{\text {th }}$, September 21-25, 1998, Vancouver, British Columbia, Canada, Proceedings: Rotterdam, Netherlands, A.A. Balkema, v. 2, pp.1157-1165.

Press, W.H., Flannery, B.P., Teukolsky, S.A., and Vetterling, W.T., 1986, Numerical recipes, the art of scientific computing: New York, Cambridge University Press, $818 \mathrm{p}$.

Quinn, P., Beven, K., Chevallier P., and Planchon, O., 1991, The prediction of hillslope flow paths for distributed hydrological modeling using digital terrain models: Hydrological Processes, v. 5 p. 59-80.

Tarboton, D.G., 1997, A new method for the determination of flow directions and contributing areas in grid digital elevation models: Water Resources Research, v. 33 no. 2, p. 309-319.

Torres, R., Dietrich, W.E., Montgomery, D.R., Anderson, S.P., and Loague, K., 1998, Unsaturated zone processes and the hydrologic response of a steep, unchanneled catchment: Water Resources Research, v.34, no.8, p.1865-1879. 
Table 1. Weighting factors for runoff distribution. The weighting factors, $w_{i j}$ are a function of the slope, $s_{i j}$, between grid cell $i$ and each neighboring downslope cell, $j$, the number of grid neighboring cells, $n$, that are downslope from cell $i$, and a user selectable exponent, $\omega$. The program automatically rounds all weighting factors to three decimal places and adjusts them so that the sum of weighting factors at each cell equals 1 . The default pattern is to divert flow only to the adjacent cell on the steepest downslope path. Weighting factors computed by TopoIndex are valid only for square cells (distance between rows equal to distance between columns).

\begin{tabular}{|c|c|c|}
\hline Exponent & Weighting factor & Distribution pattern \\
\hline$\omega<0$ & $\begin{array}{l}w_{i 1}=\left(\frac{\pi}{4}-\delta\right) /\left(\frac{\pi}{4}\right) \\
w_{i 2}=\delta /\left(\frac{\pi}{4}\right) ; \text { if two } \\
\text { cells } \\
w_{i j}=1 ; \text { if only one } \\
\text { cell }\end{array}$ & $\begin{array}{l}\text { Narrow, flow is diverted only to the one or } \\
\text { two neighboring downslope cells, } j \text { and } k \text {, } \\
\text { that straddle the steepest downslope path. } \\
\text { If the steepest downslope path is aligned } \\
\text { with a grid direction or diagonal, then flow } \\
\text { is diverted only to the neighboring cell in } \\
\text { that direction. The weighting factors } \\
\text { depend on the angle } \delta \text { between the D } 8 \\
\text { flow direction and the steepest slope. Here } \\
\text { the exponent, } \omega \text {, serves only as a flag. }\end{array}$ \\
\hline$\omega=0$ & $w_{i j}=\frac{1}{n}$ & $\begin{array}{l}\text { Fan-shaped, uniform distribution among } \\
\text { adjacent downslope cells regardless of } \\
\text { slope }\end{array}$ \\
\hline $0<\omega \leq 20$ & $w_{i j}=s_{i j}{ }^{\omega} / \sum_{j=1}^{j=n} s_{i j}{ }^{\omega}$ & $\begin{array}{l}\text { Fan-shaped, the positive value of } \omega \text { results } \\
\text { in weighting factors that favor steeper flow } \\
\text { paths. The pattern becomes more strongly } \\
\text { skewed toward the steepest downslope path } \\
\text { as } \alpha \text { increases. }\end{array}$ \\
\hline$\omega>20$ & $\begin{array}{l}w_{i j}=1 \text {; cell on } \\
\text { steepest path } \\
w_{i j}=0 \text {; other } \\
\text { downslope cells }\end{array}$ & $\begin{array}{l}\text { Narrow, flow is diverted only to the } \\
\text { neighboring cell that is on the steepest } \\
\text { downslope path (D8 method, O'Callaghan } \\
\text { and Mark, 1984) }\end{array}$ \\
\hline
\end{tabular}


Table 2. Sample listing of the initialization file "trigrs.ini"

[The file is organized with a project title on the first line of data, numerical input on lines 2-6, names to input files on the next group of lines, and selection of output files on the last group of lines. An explanatory heading precedes each line of data, and each heading occupies a single line. Some of the longer headings appear to occupy two lines in the table below; however they occupy only one line in the actual file. File path names can include up to 255 characters. Each file name occupies a single line in the file. The total number of lines in the file depends on the number of periods of different rainfall intensity; include a file path name, rifil() for each period. See table 3 for definitions of the numeric variables. In this example, the unit weight of soil and rainfall rates during the storm are set constant over the grid (see positive values in $4^{\text {th }}$ and $5^{\text {th }}$ lines). Two storm periods are specified, so two lines are needed for the rainfall rate input file names. Units in this example, time, s; length, $\mathrm{m}$; force, $\mathrm{N}\left(\mathrm{kg}-\mathrm{m} / \mathrm{s}^{2}\right)$; pressure and stress, $\mathrm{Pa}\left(=\mathrm{N} / \mathrm{m}^{2}\right)$; unit weight, $\mathrm{N} / \mathrm{m}^{3}$ ]

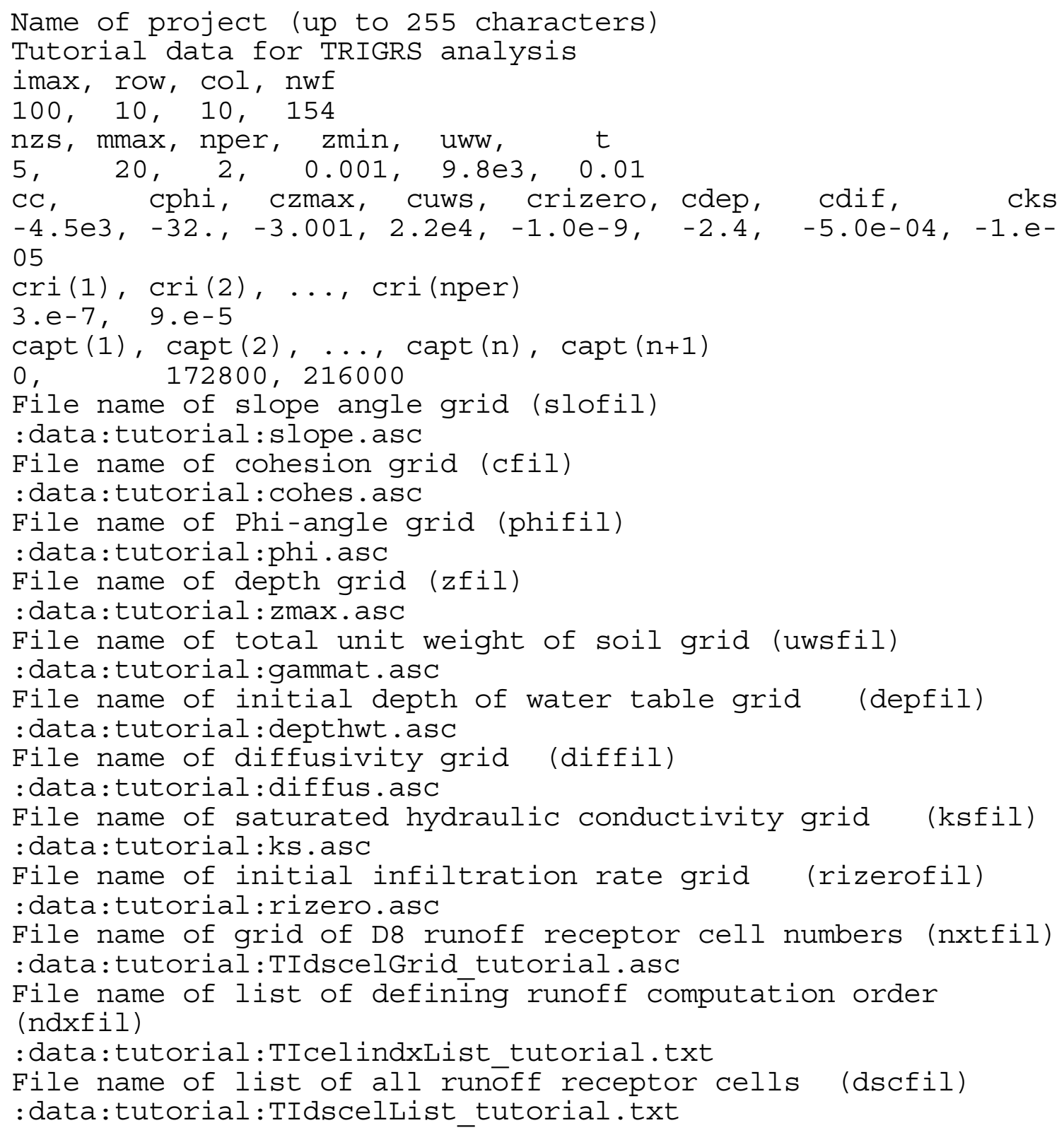


File name of list of runoff weighting factors (wffil)

:data:tutorial:TIwfactorList_tutorial.txt

List of file name(s) of rainfall intensity for each period, (rifil ())

:data:tutorial:ril.asc

:data:tutorial:ri2.asc

Folder where output grid files will be stored (folder)

:data:tutorial:

Identification code to be added to names of output files (suffix)

$t=0.01$

Save grid files of runoff? Enter $\mathrm{T}$ (.true.) or $\mathrm{F}$ (.false.)

$\mathrm{T}$

Save grid of factor of safety at maximum depth, zmax? Enter $\mathrm{T}$ (.true.) or F (.false.)

$\mathrm{T}$

Save grid of pore pressure at maximum depth, zmax? Enter $\mathrm{T}$ (.true.) or $F$ (.false.)

$\mathrm{T}$

Save grid of minimum factor of safety? Enter Enter $\mathrm{T}$ (.true.) or $F$ (.false.)

$\mathrm{T}$

Save grid of depth of minimum factor of safety? Enter Enter $\mathrm{T}$ (.true.) or F (.false.)

$\mathrm{T}$

Save grid of pore pressure at depth of minimum factor of safety? Enter Enter T (.true.) or F (.false.)

$\mathrm{T}$

Save grid files of actual infiltration rate? Enter $T$ (.true.) or $F$ (.false.)

$\mathrm{T}$

Save listing of pressure head and factor of safety ("flag")?

(Enter -2 detailed, - 1 normal, 0 none)

$-2$ 
Table 3. Definition of input variables, excluding file path names, found in the initialization file and related input files.

[See table 2 for location of each variable in the initialization file, trigrs.ini. Integers are assumed to be 4-byte integers]

Program Control

\begin{tabular}{|c|c|c|c|}
\hline $\begin{array}{l}\text { Variable } \\
\text { name }\end{array}$ & Type & Description & Range of values \\
\hline nzs & integer & Number of vertical increments & $\mathrm{nzS}>=1$ \\
\hline $\operatorname{mmax}$ & integer & $\begin{array}{l}\text { Number of terms in series solution } \\
\text { for impermeable base at finite depth, } \\
\text { maximum value of } m \text { in equation } 2 \text {, } \\
\text { also a flag to choose between a finite } \\
\text { (eq. 2) or infinite depth (eq. } 1 \text { ) } \\
\text { solution }\end{array}$ & $\begin{array}{l}\operatorname{mmax}>=1, \text { typically } \\
10<\operatorname{mmax}<25 \text {, setting } \\
\text { mmax }<1 \text { chooses the } \\
\text { original Iverson solution } \\
\text { (equation } 1 \text { ) for infinite } \\
\text { depth }\end{array}$ \\
\hline imax & integer & $\begin{array}{l}\text { Number of grid cells (excluding no- } \\
\text { data cells) }\end{array}$ & $0<\operatorname{imax}$ \\
\hline row & integer & Number of grid rows & $0<$ row $<$ imax \\
\hline $\mathrm{COl}$ & integer & Number of grid columns & $0<$ col<imax \\
\hline nwf & integer & $\begin{array}{l}\text { Length of arrays to store flow routing } \\
\text { locations and weighting factors. Set } \\
\text { equal to total number of runoff } \\
\text { weighting factors computed by } \\
\text { TopoIndex }\end{array}$ & $\operatorname{imax}<=n w f<=8 *$ imax \\
\hline flag & integer & $\begin{array}{l}\text { Output flag used to specify how } \\
\text { depth profiles are saved. }\end{array}$ & $\begin{array}{l}-1 \text { or }-2=\text { output depth } \\
\text { profile at all cells, any } \\
\text { other value, no profile } \\
\text { output }\end{array}$ \\
\hline zmin & real & $\begin{array}{l}\text { Shallowest depth at which to } \\
\text { compute pore pressures, } Z_{\text {min }}\end{array}$ & $\begin{array}{l}\text { zmin }>0, \text { typically } \\
.01<=\text { zmin }<=0.1\end{array}$ \\
\hline
\end{tabular}

Mechanical and Hydrologic Properties

\begin{tabular}{|l|l|l|l|}
\hline $\begin{array}{l}\text { Variable } \\
\text { name }\end{array}$ & Type & Description & Range of values \\
\hline uww & real & Unit weight of water, $\gamma_{w}$ & uww $>0$ \\
\hline cC & real & Soil cohesion, $c$ & $\begin{array}{l}\text { cc }>=0, \text { read values from } \\
\text { grid file if negative }\end{array}$ \\
\hline cphi & real & Angle of internal friction, $\phi$ & $\begin{array}{l}\text { cphi }>0, \text { read values from } \\
\text { grid file if negative }\end{array}$ \\
\hline cuws & real & Total unit weight of soil, $\gamma_{s}$ & $\begin{array}{l}\text { cuws }>0 \text {, read values } \\
\text { from grid file if negative }\end{array}$ \\
\hline czmax & real & Maximum depth, $Z_{\text {max }}$ & $\begin{array}{l}\text { czmax }>0, \text { read values } \\
\text { from grid file if negative }\end{array}$ \\
\hline crizero & real & Steady, pre-storm infiltration rate, $I_{Z}$ & $\begin{array}{l}\text { crizero }>0 \text {, read values } \\
\text { from grid file if negative }\end{array}$ \\
\hline cdep & real & Initial, steady depth of water table, $d$ & $\begin{array}{l}\text { 0<cdep<=zmax, read } \\
\text { values from grid file if } \\
\text { negative }\end{array}$ \\
\hline cdif & real & Hydraulic diffusivity, $D_{0}$ & $\begin{array}{l}\text { cdif }>\text { zmin, read values } \\
\text { from grid file if negative }\end{array}$ \\
\hline cks & real & $\begin{array}{l}\text { Vertical hydraulic conductivity of } \\
\text { saturated soil, } K_{Z}\end{array}$ & $\begin{array}{l}\text { cks }>0, \text { read values from } \\
\text { grid file if negative }\end{array}$ \\
\hline
\end{tabular}


Table 3. Continued

Storm Properties

\begin{tabular}{|l|l|l|l|}
\hline $\begin{array}{l}\text { Variable } \\
\text { name }\end{array}$ & Type & Description & Range of values \\
\hline nper & integer & $\begin{array}{l}\text { Number of periods of different } \\
\text { rainfall rates during a storm, } N\end{array}$ & nper $>=1$ \\
\hline$t$ & real & Elapsed time since start of storm, $t$ & $\mathrm{t}>0$ \\
\hline $\operatorname{cri}()$ & $\begin{array}{l}\text { real } \\
\text { array }\end{array}$ & $\begin{array}{l}\text { Rate of application }(\text { rainfall intensity) } \\
\text { during each storm increment, } I_{n Z}\end{array}$ & $\begin{array}{l}\text { cri()>0, read values from } \\
\text { grid file if negative }\end{array}$ \\
\hline $\operatorname{capt}()$ & $\begin{array}{l}\text { real } \\
\text { array }\end{array}$ & $\begin{array}{l}\text { Cumulative duration of storm at end } \\
\text { of each increment, } t_{n}\end{array}$ & $\begin{array}{l}\operatorname{capt}(1)=0, \\
\operatorname{capt}(1)<\operatorname{capt}(2)<, \ldots, \\
\operatorname{capt}(\mathrm{n})<\operatorname{capt}(\mathrm{n}+1)\end{array}$ \\
\hline
\end{tabular}

Runoff-Routing Parameters (found only in data files, not in initialization file)

\begin{tabular}{|l|l|l|l|}
\hline $\begin{array}{l}\text { Variable } \\
\text { name }\end{array}$ & Type & Description & Range of values \\
\hline $\mathrm{nxt}$ & $\begin{array}{l}\text { Integer } \\
\text { array }\end{array}$ & $\begin{array}{l}\text { Cell that is downslope along the } \\
\text { steepest path from the present cell }\end{array}$ & $1<=$ imax \\
\hline indx & $\begin{array}{l}\text { Integer } \\
\text { array }\end{array}$ & $\begin{array}{l}\text { Index of cell numbers from } \\
\text { (topographically) highest to lowest }\end{array}$ & $1<=$ imax \\
\hline
\end{tabular}


Table 4. Output files generated by TRIGRS

[TR identifies files generated by the program TRIGRS; XXXXXXXX denotes the userdefined identification code (as many as eight characters) used to group files from the same run. Numerals in parenthesis indicate the order in which optional files are selected in the initialization file (table 2).]

\begin{tabular}{ll}
\hline File Name & Description \\
\hline TrigrsLog.txt & $\begin{array}{l}\text { Log file, TRIGRS overwrites this file every time it } \\
\text { runs }\end{array}$ \\
TRrunoffPer\#\#\# XXXXXXXX.asc & $\begin{array}{l}\text { Grid of computed runoff during a given storm } \\
\text { period, \#\#\# designates the storm period ending at } \\
\text { time capt(\#\#\#) (1) }\end{array}$ \\
TRfs_at_zmax_XXXXXXXX.asc & $\begin{array}{l}\text { Grid of the factor of safety at the maximum depth } \\
\text { in each cell for time t (2) }\end{array}$ \\
TRp_at_zmax_XXXXXXXX.asc & $\begin{array}{l}\text { Grid of the pressure head at the maximum depth in } \\
\text { each cell for time t (3) }\end{array}$ \\
TRfs_min_XXXXXXXX.asc & $\begin{array}{l}\text { Grid of the minimum computed factor of safety at } \\
\text { each cell for time t (4) }\end{array}$ \\
TRz_at_fs_min_ & $\begin{array}{l}\text { Grid of depths at which the minimum factor of } \\
\text { safety was computed for time t (5) }\end{array}$ \\
XXXXXXXX.asc & $\begin{array}{l}\text { Grid of pressure head at the depth corresponding to } \\
\text { minimum factor of safety for time t (6) }\end{array}$ \\
TRp_at_fs_min_ & $\begin{array}{l}\text { Grid of actual infiltration rates during a given storm } \\
\text { period, \#\#\# designates the storm period ending at } \\
\text { time capt(\#\#\#) (7) }\end{array}$ \\
XXXXXXXX.asc & $\begin{array}{l}\text { Cell by cell list of pressure head and factor of safety } \\
\text { at each depth increment (see table 9). Use output } \\
\text { flag to select abbreviated, expanded or no output }\end{array}$ \\
XXXXXXXX.asc &
\end{tabular}


Table 5. Example listing of a grid file for a 10 row by 10 column grid. This particular example shows an elevation grid from the tutorial data folder. The top two lines define the number of columns and rows in the grid. The third and fourth lines indicate the coordinates of the lower-left corner of the grid, the fifth line indicates the width of the square grid cells and the sixth line defines the value used to identify cells where no data exists. The remaining lines contain the value (topographic elevation in this example) of each grid cell.

$\begin{array}{ll}\text { ncols } & 10 \\ \text { nrows } & 10 \\ \text { xllcorner } & 563435 \\ \text { yllcorner } & 5258305 \\ \text { cellsize } & 10\end{array}$

NODATA_value -9999

1031021021011009997959492

10010010099979694929088

97979695939291888582

94939290898784827976

90898786848178757472

86848380777572706969

81797674726968676871

76737169686667687173

71696866656668717476

68666565666871747781 
Table 6. Partial listing of the file "TIdscelList_tutorial.txt", which contains the cell numbers of downslope receptor cells. [The number -9999 indicates the beginning of a new cell, the next line contains the number of the grid cell, and the following lines list as many as eight adjacent cells that are downslope from the grid cell designated at the beginning of the list. The sequence repeats for each cell in the grid. If no other cells are downslope from a particular cell, such as cell 93, its cell number is indicated as the only downslope cell. Italic text in the column to the right of the numbers identifies each line of data, but does not appear in the actual output files.]

$\begin{array}{ll}-9999 & \text { separator } \\ 1 & \text { cell number } \\ 11 & \text { neighboring downslope cell number } \\ -9999 & \text { separator } \\ 2 & \text { cell number } \\ 12 & \text { neighboring downslope cell number } \\ -9999 & \text { separator } \\ 3 & \text { cell number } \\ 13 & \text { neighboring downslope cell number } \\ 14 & \text { neighboring downslope cell number } \\ -9999 & \text { separator } \\ 4 & \text { cell number } \\ 15 & \text { neighboring downslope cell number } \\ & \\ .6 & \\ -9999 & \text { separator } \\ 92 & \text { cell number } \\ 93 & \text { neighboring downslope cell number } \\ -9999 & \text { separator } \\ 93 & \text { cell number } \\ 93 & \text { neighboring downslope cell number } \\ -9999 & \text { separator } \\ 94 & \text { cell number } \\ 94 & \text { neighboring downslope cell number } \\ -9999 & \text { separator } \\ 95 & \text { cell number } \\ & \text { neighboring downslope cell number } \\ & \end{array}$


Table 7. Partial listing of the file " TIwfactorList_tutorial.txt " containing the weighting factors of downslope cells. In this example, the weighting factors are based on the $D \infty$ method. [The number -9999 indicates the beginning of a new cell, the next line contains the number of the grid cell, and the following lines list weighting factors corresponding to cells listed in table 6 . The sequence repeats for each cell in the grid. If no other cells are downslope from a particular cell, such as cell 93, it receives a weighting factor of 1. Italic text in the column to the right of the numbers identifies each line of data, but does not appear in the actual output files.]

$\begin{array}{cl}-9999 . & \text { separator } \\ 1 & \text { cell number } \\ 1.000 & \text { weighting factor for neighboring downslope cell } \\ -9999 . & \text { separator } \\ 2 & \text { cell number } \\ 1.000 & \text { weighting factor for neighboring downslope cell } \\ -9999 . & \text { separator } \\ 3 & \text { cell number } \\ 0.410 & \text { weighting factor for neighboring downslope cell } \\ 0.590 & \text { weighting factor for neighboring downslope cell } \\ -9999 . & \text { separator } \\ 4 & \text { cell number } \\ 1.000 & \text { weighting factor for neighboring downslope cell } \\ \ldots & \\ 9 & \end{array}$


Table 8. Partial listing of the file " TIcelindxList_tutorial.txt ", which contains the cell index for a grid of 100 cells taken from the tutorial data set. [The first column indicates the index or pointer to each cell listed in the second column. Cell numbers are counted from left to right across rows and from top to bottom, beginning at the upper left corner of the grid and no-data cells are unnumbered. Thus, in this example, the first cell (upper left corner, table 5) has the highest elevation in the grid so computation to partition the precipitation input between infiltration and runoff begins at the highest cell and skips around the grid in order of decreasing elevation until reaching the lowest cell in the grid].
11
22
33
44
55
611
$\begin{array}{ll}7 & 12\end{array}$
813
96
1014
$\begin{array}{ll}11 & 21\end{array}$
1222

$88 \quad 69$

8975

9067

9168

9277

9392

9476

9584

9686

9795

$98 \quad 85$

9994

10093 
Table 9. Partial listing of the TRIGRS output file " TRlist_z_p_fs_XXXXXXXX.txt ", which contains pressure $\&$ factor of safety profile for each cell. Values appearing in the actual file may differ from those listed here, depending upon the user's choice of input parameters.

[The first line contains the cell number and the slope angle in degrees; the next six lines contain six columns of fixed-width output. The first column lists the depth, the next three list the pore pressure, as pressure head at that depth (column two, total pressure head; column three, initial pressure head; column four, transient pressure head), column 5 lists the steady flow pressure cutoff and the sixth lists the factor of safety. The sequence repeats for the next cell starting on the eighth line. The number of lines of (five-column) output for each cell is one plus the number of vertical increments $(1+\mathrm{nzs}$, see fig. 7$)$. Output shown below results when flag is set to -2 , if flag is set to -1 , then the third, fourth and fifth columns are omitted.]

\begin{tabular}{|c|c|c|c|c|c|}
\hline $\begin{array}{ll}Z & \\
1 & 16.7000\end{array}$ & $\mathrm{P}$ & Pzero & Ptran & Pbeta & FS \\
\hline $0.10000 \mathrm{E}-02$ & $0.91741 \mathrm{E}-03$ & -0.91650 & 5.5674 & $0.91741 \mathrm{E}-03$ & 10.000 \\
\hline 0.48080 & 0.44109 & -0.47632 & 5.1009 & 0.44109 & 0.86418 \\
\hline 0.96060 & 0.88127 & $-0.36146 \mathrm{E}-01$ & 4.6608 & 0.88127 & 0.84360 \\
\hline 1.4404 & 1.3214 & 0.40403 & 4.2470 & 1.3214 & 0.83672 \\
\hline 1.9202 & 1.7616 & 0.84420 & 3.8590 & 1.7616 & 0.83329 \\
\hline $\begin{array}{l}2.4000 \\
2 \quad 11.3000\end{array}$ & 2.2018 & 1.2844 & 3.4965 & 2.2018 & 0.83122 \\
\hline $0.10000 \mathrm{E}-02$ & $0.96160 \mathrm{E}-03$ & -0.96063 & 5.6999 & $0.96160 \mathrm{E}-03$ & 10.000 \\
\hline 0.48080 & 0.46233 & -0.49926 & 5.2331 & 0.46233 & 1.2947 \\
\hline 0.96060 & 0.92371 & $-0.37887 \mathrm{E}-01$ & 4.7921 & 0.92371 & 1.2652 \\
\hline 1.4404 & 1.3851 & 0.42349 & 4.3767 & 1.3851 & 1.2553 \\
\hline 1.9202 & 1.8465 & 0.88486 & 3.9867 & 1.8465 & 1.2504 \\
\hline $\begin{array}{l}2.4000 \\
3 \quad 12.0000\end{array}$ & 2.3078 & 1.3462 & 3.6216 & 2.3078 & 1.2474 \\
\hline $0.10000 \mathrm{E}-02$ & $0.95676 \mathrm{E}-03$ & -0.95581 & 5.6856 & $0.95676 \mathrm{E}-03$ & 10.000 \\
\hline 0.48080 & 0.46001 & -0.49675 & 5.2188 & 0.46001 & 1.2174 \\
\hline 0.96060 & 0.91907 & $-0.37696 \mathrm{E}-01$ & 4.7779 & 0.91907 & 1.1895 \\
\hline 1.4404 & 1.3781 & 0.42136 & 4.3627 & 1.3781 & 1.1802 \\
\hline 1.9202 & 1.8372 & 0.88041 & 3.9728 & 1.8372 & 1.1755 \\
\hline 2.4000 & 2.2962 & 1.3395 & 3.6080 & 2.2962 & 1.1728 \\
\hline
\end{tabular}


Table 10A. Example listing of entries in the initialization file for the program

TopoIndex, "topoindex.ini"

[File path names are limited to 255 characters; "Rows", "Columns", and "Number of iterations" are positive integers. "Exponent" is a real number as defined in table 1. The default folder for storing output is the folder where the program TopoIndex resides]

Name of project (up to 255 characters)

Tutorial data for TopoIndex analysis

Rows, Columns, flow-direction numbering scheme (ESRI=1, TopoIndex $=2$ )

$10, \quad 10, \quad 2$

Exponent, Number of iterations

$25, \quad 10$

Name of elevation grid file

:data:tutorial:dem.txt

Name of direction grid

:data:tutorial:directions.txt

Save listing of D8 downslope neighbor cells? Enter T (.true.) or F (.false.)

T

Save grid of D8 downslope neighbor cells? Enter T (.true.) or F (.false.)

T

Save cell index number grid? Enter T (.true.) or F (.false.)

$\mathrm{T}$

Save list of cell number and corresponding index number? Enter T (.true.) or F (.false.)

T

Save flow-direction grid remapped from ESRI to TopoIndex? Enter T (.true.) or F (.false.)

$\mathrm{T}$

Name of folder to store output? Leave blank to use default folder

:data:tutorial:

Identification code for output files? (8 characters or less)

tutorial 
Table 10B. Names of TopoIndex output files.

[TI identifies files generated by the program TopoIndex; XXXXXXXX denotes the userdefined identification code used to group files from the same run. Numerals in parenthesis indicate the order in which optional files are selected in the initialization file (table 10A).]

\begin{tabular}{ll}
\hline File Name & Description \\
\hline TopoIndexLog.txt & $\begin{array}{l}\text { Log file, TopoIndex overwrites this file every time } \\
\text { it runs }\end{array}$ \\
TIdsneiList_XXXXXXXX.txt & $\begin{array}{l}\text { List of downslope receptor cells in D8 flow } \\
\text { direction (1) } \\
\text { *Grid of downslope receptor cells in D8 flow } \\
\text { TIdscelGrid_XXXXXXXX.asc }\end{array}$ \\
TIcelindxGrid_XXXXXXXX.asc (2) & $\begin{array}{l}\text { Grid of cell index numbers that specify computation } \\
\text { order for runoff routing in TRIGRS (3) }\end{array}$ \\
TIcelindxList_XXXXXXXX.txt & $\begin{array}{l}\text { *ist of cell numbers and corresponding index } \\
\text { number (computation order) (4) }\end{array}$ \\
TIflodirGrid_XXXXXXXX.asc & $\begin{array}{l}\text { Flow-direction grid in terms of the TopoIndex } \\
\text { numbering scheme shown in figure 5. (5) } \\
\text { *Cell by cell list of downslope cells for which non- }\end{array}$ \\
TIdscelList_XXXXXXXX.txt & $\begin{array}{l}\text { zero weighting factors have been computed } \\
\text { *Cell by cell list of weighting factors for downslope } \\
\text { receptor cells }\end{array}$ \\
\hline
\end{tabular}

*Required by TRIGRS for runoff routing 


\section{Appendix A. Listing of files included in this distribution}

Folder names appear below in boldface type and indentation indicates folder hierarchy. File suffixes for make files and compiled programs vary between operating systems; the ".exe" and ".amk" suffixes used below correspond to the Windows convention. TRIGRS

Data

flume

slope.asc

TIcelindxList_flume.txt

TIdscelGrid_flume.asc

TIdscelList_flume.txt

TIwfactorList_flume.txt

\section{MinorCreek}

slope.asc

TIcelindxList_MC.txt

TIdscelGrid_MC.asc

TIdscelList_MC.txt

TIwfactorList_MC.txt

tutorial

c.asc

cohes.asc

dem.asc

depthwt.asc

diffus.asc

directions.asc

gammat.asc

ks.asc

phi.asc

ril.asc

ri2.asc

rizero.asc

slope.asc

TIcelindxList_tutorial.txt

TIdscelGrid_tutorial.asc

TIdscelList_tutorial.txt

TIwfactorList_tutorial.txt

zmax.asc

\section{Documentation}

OFR-02-0424.pdf

\section{Source}

\section{TopoIndex}

isvgrd.f

mpfldr.f

nxtcel2.f 
rdflodir.f

sindex.f

slofac.f

srdgrd1.f

TopoIndex.amk

tpindx.f90

\section{TRIGRS}

calerf.f

derfc.f

irdgrd.f

irdswm.f

iverson.f

savage.f

srdgrd.f

srdswm.f

ssvgrd.f

TRIGRS.amk

trigrs. 90

\section{UnitConvert}

srdgrd.f

ssvgrd.f

unitconvert.amk

unitconvert.f90

memoryReq.xls

TopoIndex.exe

topoindex.ini

TRIGRS.exe

trigrs.ini

trigrsflume.ini

trigrsMC.ini

unitconvert.exe

unitconvert.ini 


\section{Appendix B. Tutorial}

We have provided a data set for a 100-cell (10 cells wide by 10 cells long) grid to demonstrate use of TRIGRS, along with separate single-cell grids for reproducing Iverson's (2000) flume and Minor Creek landslide analyses. These data sets are found in separate folders within the folder "data" and include a complete set of files for topographic, precipitation, and physical properties data, along with necessary data for routing runoff, where applicable (fig. B1 and Appendix A). The following paragraphs describe use of the programs TopoIndex and TRIGRS and how a user controls an analysis by editing the initialization files. Data for this exercise are found in the folder "tutorial", within the "data" folder. By following the instructions in this tutorial, the user will analyze a small sample problem that illustrates many of the features of problems that TRIGRS is capable of analyzing. The sample problem includes spatially variable geometry and physical properties data, a spring, and two-stage (spatially uniform) rainfall. The tutorial analysis illustrates development of local runoff, gradual build-up of pore pressure as a result of infiltration, and local slope failure at the end of the storm. Before starting, make sure that your system preferences are set to show file extensions ${ }^{6}$ and that you have a suitable plain text editor installed on your system. ${ }^{7}$

\section{Using Topolndex to prepare data for runoff routing}

Use the program TopoIndex at the beginning of a project to prepare data needed for runoff routing in TRIGRS. Once a topographic data set and routing method are selected for a study area, the output of TopoIndex can be reused for multiple analyses of that area by TRIGRS.

Open the folder TRIGRS and double click the icon "topoindex.ini" to open the file and view its contents; it should resemble table $10 \mathrm{~A}$ in the main text. A line of explanatory text precedes each line of data; the text identifies the data on the succeeding line. The user must specify a title, the number of rows and columns in the grid, the numbering scheme of the (input) direction grid (fig. 6$)$, an exponent ( $\omega$, table 1 ) that determines the flow distribution weighting factors, the maximum number of iterations for indexing the cells, and the names of input files. The user may also select certain output files, enter an identification code that will help group the files from a given run, and may specify the folder where the files will be stored.

The number of rows and columns appears in the heading of the grid files. Open the elevation grid file "dem.asc" in the folder "TRIGRS/data/tutorial" to verify that the number of rows and columns listed in "topoindex.ini" agrees with corresponding numbers in the grid file (fig. B2). As explained in table 5 of the text, the top two entries of the grid

\footnotetext{
${ }^{6}$ If Windows is not set to display file extensions, select "Folder Options" from the "View" menu (Windows 98 or the "Tools" menu in Windows 2000) at the top of the "TRIGRS" folder window. Click on the "View" tab in the "Folder Options" window and uncheck the box next to "Hide file extensions for known file types" and then click "OK" to save the change. Mac OS 8 and 9 does not use extensions, so file extensions are always displayed as part of a file name. To show extensions in Mac OS X, click the pointer on a vacant spot on the desktop to make the "Finder" active and then select "Preferences" from the "Finder" menu. Check the box next to "Always show file extensions" and then click the red button in the upper left corner of the "Finder Preferences" window to save the change and close the window.

${ }^{7}$ The user should be able to open and modify plain-text files using the default text editor supplied with the computer's operating system. However, Mac OS users may benefit by downloading and using a freeware text editor, such as "BBEdit Lite" to work with the plain-text files rather than using the default editors, "SimpleText" or "TextEdit", which have limited capabilities.
} 
file indicate the number of rows and columns. If necessary, correct the number of rows and columns in the initialization file and then close the grid file.

Open the direction grid file, "directions.asc" (in the same folder) to determine which grid-direction numbering scheme is used in the file. Compare the values listed in the grid to figure 6 . If the grid values range from 1 to 9 , then the initialization file should contain the numeral 2 at the end of its second line of data to indicate that the grid uses the TopoIndex numbering scheme. If the numbers in the grid are powers of two ranging from 1 to 128, then the initialization file should contain the numeral 1 at the end of the second line of data (the project title constitutes the first line of data) to indicate that the grid uses the ESRI numbering scheme. When finished checking the numbering scheme, close the direction-grid file.

The exponent selects one of the runoff routing methods defined in table 1. Figure B3 shows example results for various exponents. Return to the initialization file, "topoindex.ini" and look at the exponent, on the third line of data (fig. B4). We suggest starting with any negative exponent, which selects the $D \infty$ method. If greater dispersion is needed to distribute water more smoothly across the slope, then choose a small positive exponent. Use a large positive exponent to minimize the dispersion. After deciding on an appropriate value for the exponent, enter it on the third line of data in the initialization file (fig. B4).

As we described previously, TopoIndex uses an iterative process to determine the order in which runoff calculations should proceed. The maximum number of iterations needed to complete the indexing process varies with the size of the grid. Our limited experience with grids of various sizes indicates that the following formula can estimate the maximum number of iterations.

iterations $\leq 1+\frac{\text { rows }+ \text { columns }}{20}$

Verify that the maximum number of iterations listed in the initialization file (fig. B5) is at least as large as indicated by the above formula. For a 10x10 grid, allow at least two iterations. The purpose in setting the maximum number of iterations is to allow TopoIndex to stop after a reasonable time in case the DEM is not hydrologically consistent and indexing cannot converge. TopoIndex will stop after the index solution converges or the maximum number of iterations is reached. Consequently, in certain cases the user may need to try a larger number of iterations than suggested above in order to achieve convergence.

Verify the names of the input files that are listed in the initialization file (fig. B6). The tutorial folder ("TRIGRS/data/tutorial") should contain files named "dem.asc" and "directions.asc". In the initialization file, the name (path) consists of the folder name followed by a separator and the file name. The separator is a colon (:) for the Mac OS or a backslash $(\backslash)$ for Windows (note that a colon also precedes the folder name for Mac OS). The combination of folder and file name can be as long as 255 characters. To avoid using folder or path names, the user can copy the executable file and initialization file to the folder that contains the input data files. Please consult the documentation for your computer's operating system to learn more about rules for specifying file path names.

Verify that the necessary output files are selected for output. A "T" should appear on the line below the question "Save grid of D8 downslope receptor cells?" and the question "Save list of cell number and corresponding index number?" (fig. B7). These two files are needed to run TRIGRS later in the tutorial. For now, an "F" should appear below the 
other three questions that ask about saving files. Verify that the specified output folder is "dataltutorial" (second to last line of data in the initialization file). The folder name should be typed "dataltutoriall" for a Windows PC or ":data:tutorial:" for a Mac OS computer. Type an identification code of eight characters or less on the last line of the initialization file (in this case we have used "tutorial"). Be sure to use only characters that your computer's operating system allows for file and folder naming.

Close the file "topoindex.ini" and double-click the program icon for TopoIndex. The program will run and then exit, closing its window. Open the folder "Tutorial" and then open the files "TIdscelList_tutorial.txt", "TIwfactorList_tutorial.txt", and "TIcelindxList_tutorial.txt", to examine their contents. Partial listings of these files appear in tables 6, 7, and 8. The file "TIcelindxList_tutorial.txt" lists cells in their correct order from highest to lowest elevation; the left column contains the index, or pointer, and the right column contains the cell number for each index value (table 8). Cell numbers increase from left to right, row by row from top to bottom, skipping any no-data cells (fig. 8). Cell numbers in the file "TIdscelList_tutorial.txt" (table 6) correspond to weighting factors in the file "TIwfactorList_tutorial.txt" (table 7 and fig. B3). When finished studying the output, close the files. At this point, either experiment with calculating the weighting factors by different methods (by changing the value of the exponent in "topoindex.ini") or proceed with the tutorial.

\section{Preparing the TRIGRS initialization file for an analysis}

We will now perform a sample analysis of slope stability using TRIGRS for the same grid we processed using TopoIndex. Understanding correct set-up of the initialization file is essential to successful use of TRIGRS. Return to the folder TRIGRS and double click the icon "trigrs.ini" to view its contents; it should resemble table 2. Notice that an explanatory heading precedes each line of data, except that the names of the rainfall-intensity files are listed on succeeding lines under a single heading. Tables 2 and 3 define the entries in the initialization file and indicate permissible ranges of values. Table 4 identifies output files, most of which are optional and can be selected in the initialization file.

Array sizes.-- Compare the array parameters on the second line of the initialization file against values that were computed by the program TopoIndex (figure B8). In the TRIGRS folder, open the file TopoIndexLog.txt and find the line of text "Data cells, Rows, Columns, Downslope cells" near the bottom of the list. Compare the corresponding numerical values in the line following with the four values on the second line of data in "trigrs.ini". If any of the numbers differ, change the values in "trigrs.ini" to agree with their corresponding values in "TopoIndexLog.txt". TRIGRS uses these numbers to allocate storage and the program will quit spontaneously or report an arrayboundary error if these numbers are too small.

Simulation parameters.-- Several parameters that control the nature of a given simulation are included on the third line of the initialization file (fig. B9). The number of vertical increments (nzs, fig. 7) determines how detailed the simulation is with depth. Choose the smallest number of increments that gives sufficient detail when analyzing large grids, because computation time increases directly with the number of vertical increments. The sign of mmax determines whether pore pressures are computed using equation 1 or equation 2. Setting mmax to a negative value selects Iverson's (2000) solution for infinite depth (equation 1) and a positive value selects the solution for finite depth (equation 2). A positive value of mmax determines how many terms of the infinite series in equation 2 will be used in computing the pore pressures. Our tests indicate that the series converges rapidly and that 20 terms yield sufficient accuracy for most purposes. Both formulas, (equations 1 and 2) are able to compute pore pressures for 
multi-stage storms. The rainfall periods, nper, correspond to individual bars in the rainfall histogram of figure 4 . The tutorial data has two periods. A spatially constant rainfall value (fifth line of data) or grid of spatially variable rainfall must exist for each period. Set the minimum depth, zmin, to a small positive value $(.001 \mathrm{~m}$ in this example, table 2) to investigate transient infiltration and slope-stability from just below the surface downward to the maximum depth. Enter a value for the unit weight of water, uww, to establish the units of measurement for your other data. In this case, we are using meterkilogram-second units, and the unit weight of water is approximately $9800 \mathrm{Kgm} / \mathrm{s}^{2} \mathrm{~m}^{3}$. Finally, enter the elapsed time, $t$, since the beginning of the storm. To compute conditions at the beginning of the storm, we have entered 0.01 seconds for this example because entering a value of zero may result in an error. On successive runs, insert increasing values for the elapsed time to compute the results as a time-series.

Physical parameters.-- Many of the input parameters for physical properties and precipitation input can be set to constants or read from a grid. The fourth line of data in the initialization file contains a list of physical parameters (fig. B10). The parameters must be listed in the following order: $c, \phi, Z_{\max }, \gamma_{s}, I_{Z}, d, D_{0}, K_{Z}$. Enter a positive value for each parameter in the simulation that is constant across the study area, a negative value to read from a grid so that the parameter can vary spatially. For example, the fourth value on the fourth line of data is $\gamma_{s}$ (cuws), which has the value $2.2 \mathrm{e} 4$. It is positive, so that value will be applied at each grid cell. The last value at the end of the third line of data is, $K_{Z}$ (cks). We want to read $K_{Z}$ from a grid file, so verify that the value under cks in "trigrs.ini" is -1.e-5 and that the correct name of the file appears on line 13 of the initialization file. In this case, the file name is correct, as the user can verify by locating the file "ks.asc" in the tutorial data folder. For this example, most parameters are read from grids as evidenced by their negative values.

Rainfall intensities. -- The fifth line of data lists rainfall intensities corresponding to the number of periods of distinct rainfall intensity. The intensities should be listed in their correct temporal order. Two values are listed, corresponding to the two periods in this example (fig. B11). The rainfall rates are in meters per second. As with the physical parameters, entering a negative intensity causes TRIGRS to read rainfall intensity from a grid file for the corresponding time period.

Time increments. -- The sixth line of numerical data in the initialization file contains times that define the rainfall periods as defined in figure 4 . These should be listed in their correct temporal order so that the numbers increase from left to right. Three times are listed in "trigrs.ini" for this example (fig. B12). The first time, $0 \mathrm{~s}$, is at the beginning of the rainfall; the remaining times correspond to the end of each rainfall period and beginning of the next. Thus, period one, which has an intensity of $3 \times 10-7 \mathrm{~m} / \mathrm{s}$ ends after 172,800 seconds and period two begins. After 216,000 seconds, period two, which has an intensity of $9 \times 10-5 \mathrm{~m} / \mathrm{s}$, ends. Thus period two lasts 43,200 seconds $(216,000-$ $172,800)$.

Input files. -- The next group of lines lists the names of the input files in the order in which TRIGRS expects them (fig. B13). All the files are in the tutorial data folder, so the folder name precedes the name of each file as described previously. Verify that the folder name agrees with the location of the input files. In addition to a file corresponding to each physical parameter listed on line 4, the listing includes files for slope angle, rainfall intensity, and runoff routing data. Note that the number of files for rainfall intensity must equal the number of storm periods and that all are grouped under one heading. Two rainfall intensity files are listed in this example. Supply a placeholder, such as "none" for the names of any file names that do not exist. For example, if you assume that the soil cohesion is constant over the entire area, you probably would not create a grid file for cohesion. In that case, you would enter a positive constant for the 
cohesion on line 4 and type "none" below the heading that asks for the name of the soil cohesion grid file (fig. B14).

Output files. --The log file, "TrigrsLog.txt", is generated automatically, all others are optional. Figure B15 shows the group of lines in the initialization file that control output. If desired, you may supply the name of a folder where the output files will be stored. In this case, TRIGRS will write the files in the folder named ":data:tutorial:"

("dataltutorial" for the Windows version) within the TRIGRS folder. Leave the line blank if you wish to put the files in the same folder where the TRIGRS executable program file resides. If desired, provide an identification code (as many as 8 characters) for output files, otherwise leave a blank line. For this example, the code " $t=0.01 "$ corresponds the time since rainfall began, specified earlier. Be sure to change the code before running the next simulation. Generation of individual output grid files can be turned on or off by typing "T" or " $F$ " on the corresponding line of the initialization file. Table 4 of the main text describes the various output files. An output flag at the end of the initialization file controls output of a detailed listing of pressure head and factor of safety by depth for each grid cell. Make sure that all of the grid files are turned on (T) and that the output flag is set to -2 to generate a full list like that in table 9 . If working with large grids, you may want to suppress output of the detailed listing by setting the flag to 0 (zero) to save disk space.

\section{Using TRIGRS to Analyze Slope Stability during a Simple Storm}

After studying and editing the initialization file, close the file and double-click the TRIGRS application icon to perform an analysis. TRIGRS will attempt to open an initialization file named "trigrs.ini" in the same folder as the TRIGRS application resides. If TRIGRS does not find the file, it will prompt the user to enter the name of the initialization file. After finding the initialization file, TRIGRS should run without any additional intervention by the user, then quit, closing its window. After TRIGRS quits, you can open the output files in the folder "data/tutorial" to see the results. In this analysis, time was set to a small value $(0.01 \mathrm{~s})$, near zero, to compute conditions at the beginning of the storm. To save these results before conducting another analysis, add the identification code to the name of the log file (change it to "TrigrsLogt=0.01.txt") and move it to the folder with the output data so you have a record of what input parameters were used. Next edit the initialization file to change the time, identification code and any other parameters, before running TRIGRS again. TRIGRS does not have any display capabilities. To observe your results graphically, import the ASCII grid output files into graphics or GIS software.

Time steps. --A typical analysis will involve running TRIGRS for several different times throughout the duration of a storm to observe how pore pressure and slope stability vary as the storm progresses. To observe pore pressures at a later time, open "trigrs.ini" and edit the time (last value on the third line of data). For example, change the elapsed time from $0.01 \mathrm{~s}$ to $43200 \mathrm{~s}$ and run TRIGRS again to observe the pore pressure and factor of safety at the middle of the first storm period. Then repeat for $86400 \mathrm{~s}$ and $100800 \mathrm{~s}$ to compute pressure head at the end of the first and second storm periods. After each analysis, be sure to save the log file by renaming and moving it as described above.

Figure B16 shows graphical representation of the input data and the results of the analysis for the hypothetical ten-cell by ten-cell study area that is represented by the tutorial data grids.

Input data. --The digital elevation model (DEM, fig. B16) represents part of a small canyon that drains to the southwest. Geologic material that underlies the upper left part of the area has higher shear strength parameters (cohesion and phi, fig. B16), and lower hydraulic conductivity, $K_{S}$, and diffusivity, $D_{S}$, than material in the remainder of the 
area. The depth to firm bedrock is assumed to be $2 \mathrm{~m}$ everywhere except on slopes that are steeper than $30^{\circ}$, where depth decreases linearly with increasing slope angle. The precipitation data represent a hypothetical 28-hour storm that consists of 24 hours of steady, light precipitation followed by four hours of heavy precipitation. We have assumed uniform precipitation over this small area. The steady infiltration rate (not shown) is also uniform across the area, except at a spring located in the channel bottom. A negative infiltration rate in the seventh column and eighth row of the grid "rizero.asc" represents discharge from the spring.

Results. - Three series of plots in figure B16 show the runoff and progressive changes in pressure head, $\psi$, and factor of safety, FS. Runoff occurred during both phases of the storm (RUNOFF 1 and 2 in fig. B16). The precipitation rate is higher than the hydraulic conductivity of material in the upper left so that water runs off it and infiltrates into the more permeable material downslope, as reflected by the higher infiltration rates directly downslope from the contact between materials of higher and lower conductivity (INFILTRATION 1 and 2, Fig. B16). As a result, pressure head increased more rapidly downslope from the contact between the two materials. A spring exists at the channel bottom in the lower left corner of the area, which also produces runoff during both storm periods. Pressure head increased very little in the less permeable material, in the upper left corner of the area, but increased steadily throughout the storm in the more permeable material. Likewise, factor of safety changed gradually during the storm, and many of the steep cells become unstable by the end of the storm (Fig. B16).

Starting a new problem. -- Having completed the tutorial, you should now be ready to set up and solve a new problem. Use GIS software to create the input grids and save them in the required ASCII format. Create a new folder for all the input data (preferably in the TRIGRS "Data" folder) and copy all of the data files for the new problem into the new folder. Make a copy of the initialization file and rename both the original file and the copy. If any of the initialization files in the TRIGRS folder are named "trigrs.ini," be sure that it is the active (new) one. However, to avoid confusion, it might be best to give the all the initialization files descriptive names and enter the name of the one you want to use at run time. After creating and naming a new initialization file, open it in a text editor and enter the correct folder and file names for your new problem into the new initialization file. Also, be sure to edit the project title all the other input parameters to suit the new problem. 


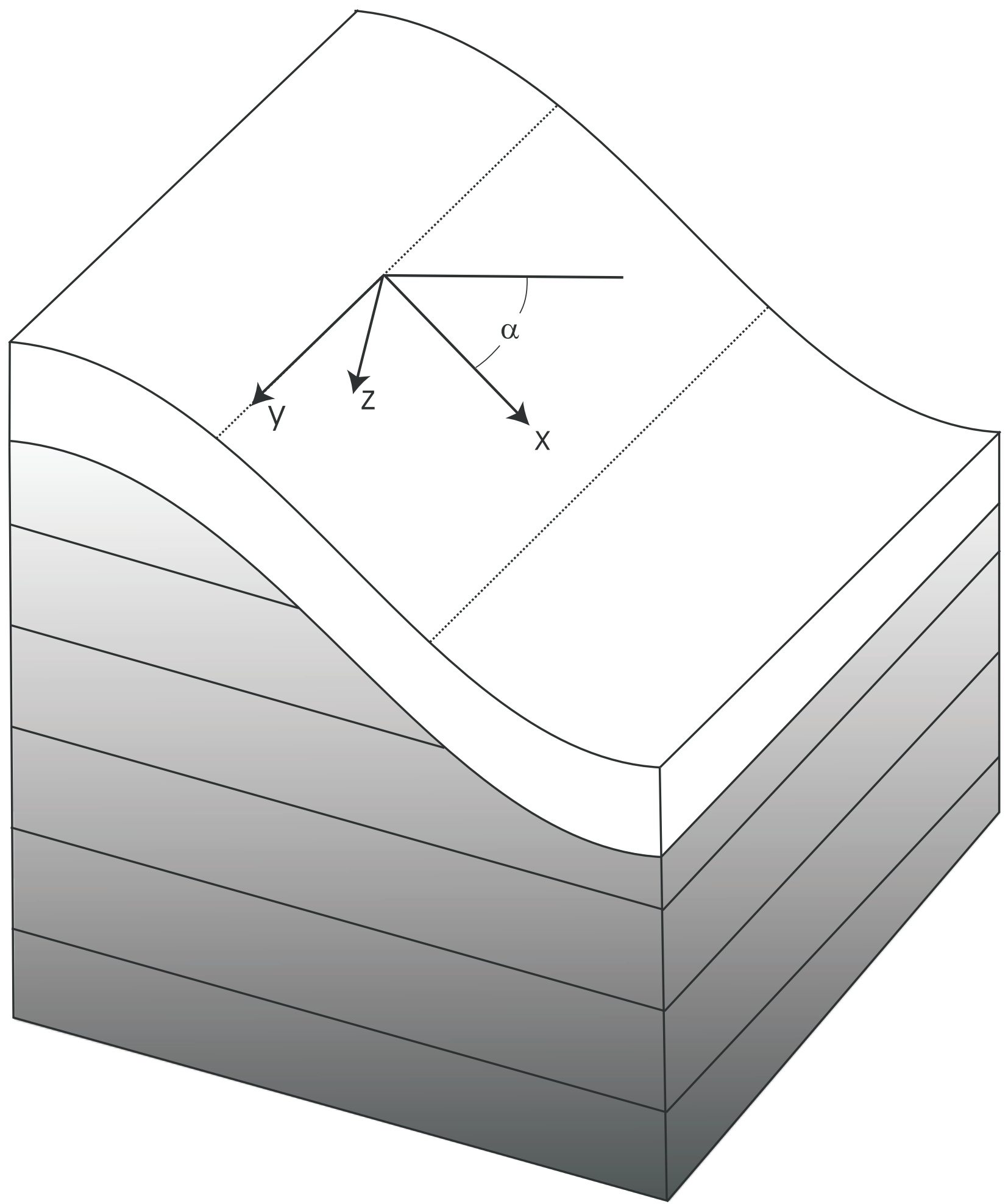

Figure 1. Sketch showing local $x y z$ coordinate system with $y$ tangent to the local surface slope, $y$ tangent to the local topographic contour, $z$ normal to the $x y$-plane, and the slope angle, $\alpha$, is with respect to the horizontal. 


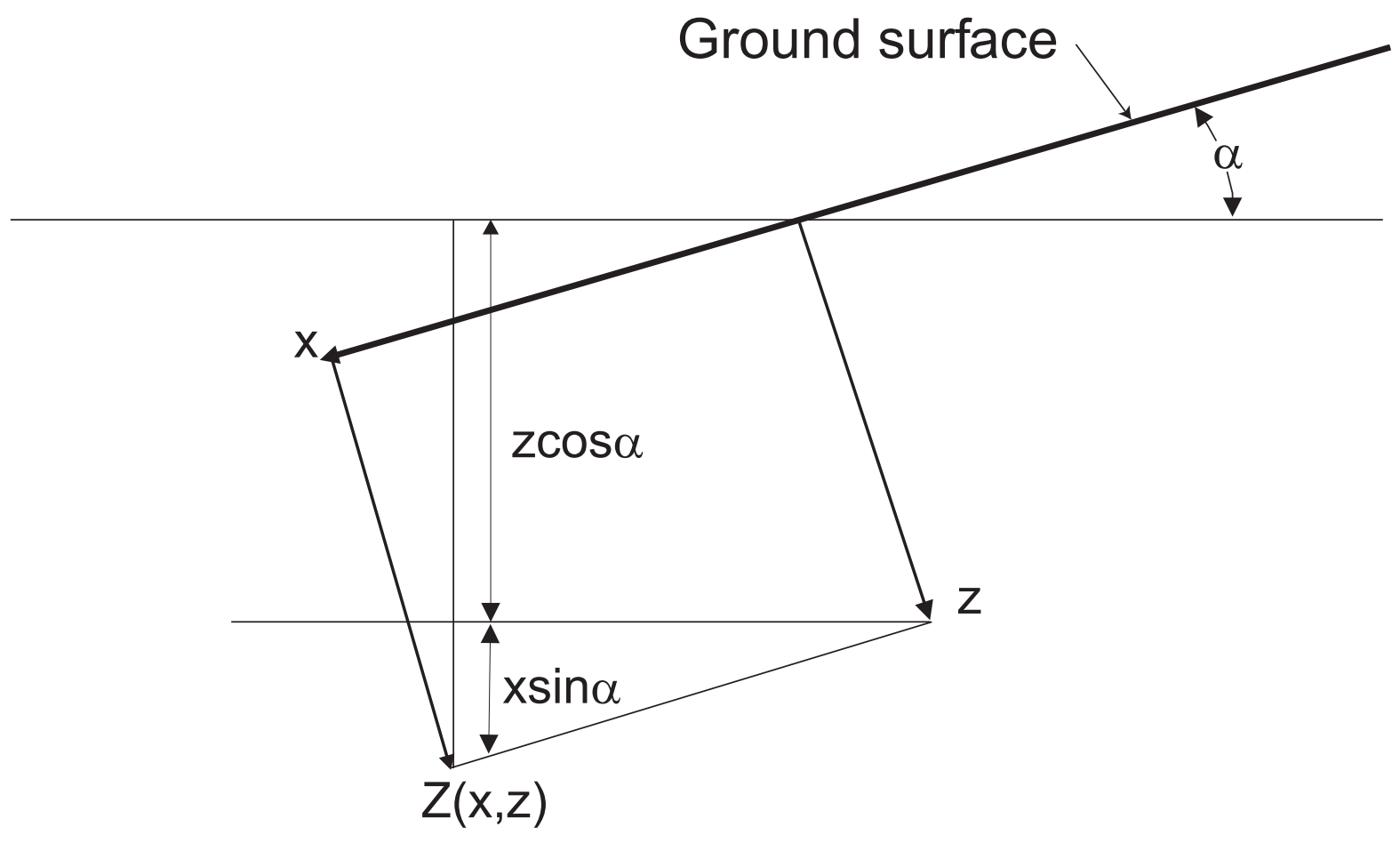

Figure 2. Sketch showing the definition of the vertical coordinate, $Z=x \sin \alpha+z \cos \alpha$, used to compute the depth at an arbitrary location. If $Z$ and $z$ have a common origin, then $z / \cos \alpha$ (after Iverson, 2000). 


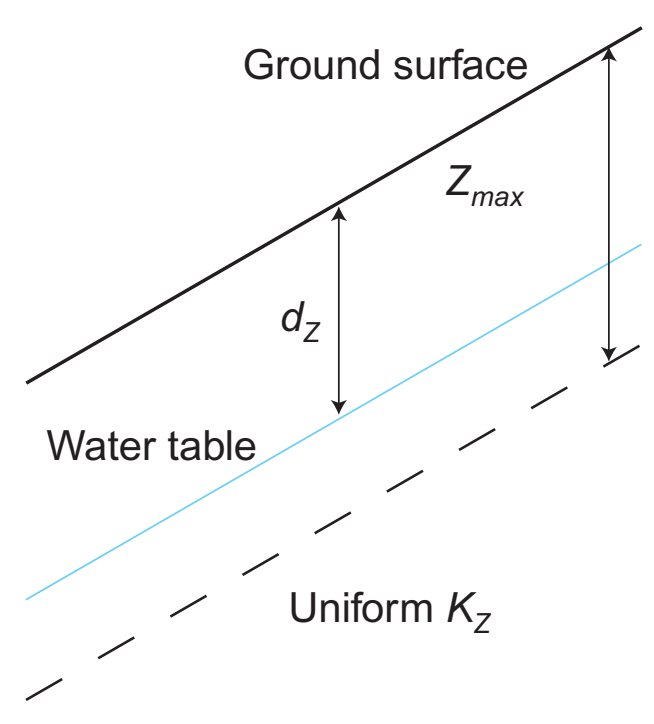

A.

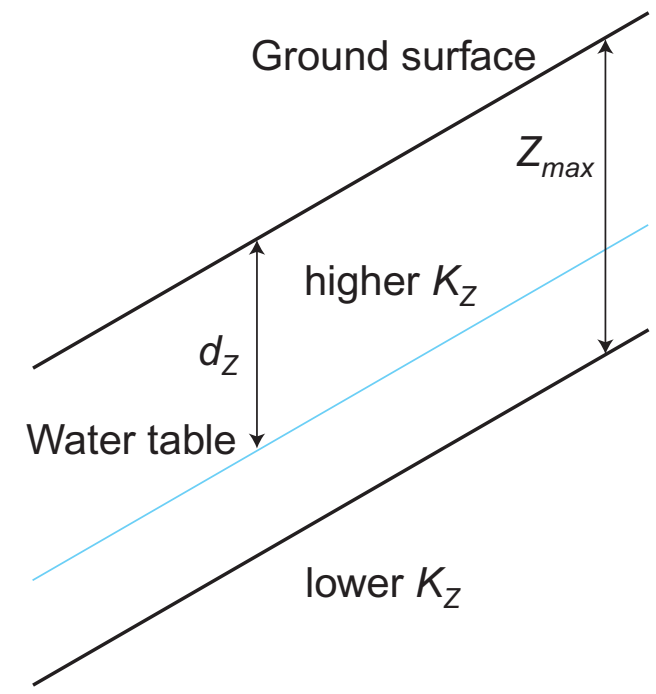

B.

Figure 3. Schematic cross sections showing boundary conditions assumed in deriving the two infiltration formulas (equations 1 and 2). The dimension $Z_{\max }$ corresponds to the input variable $z \max$, and the initial depth to the water table, $d$, corresponds to the input variable $c d e p$ (table 3 ). A. The infinite-depth boundary condition, which is assumed in equation 1, is appropriate for areas where the vertical hydraulic conductivity is relatively uniform with depth. $B$. The finite-depth boundary condition, which is assumed in equation 2, is appropriate where a more permeable surficial layer overlies a less permeable substrate, such as regolith over bedrock. 


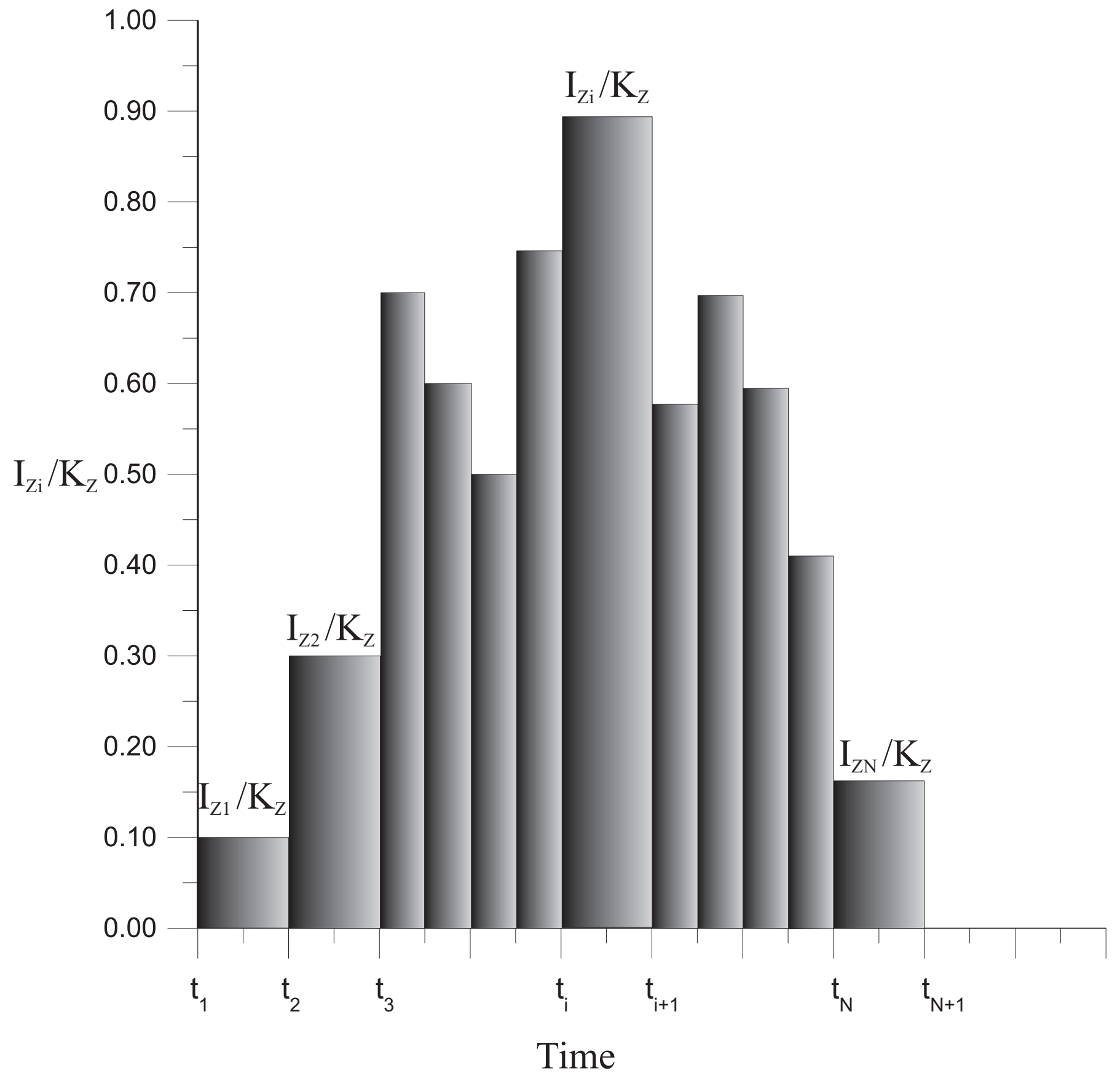

Figure 4. Hypothetical rainfall history of varying duration and intensity. In practice, the initial time, $\mathrm{t}_{1}$ is set to zero. Times $t_{1}, \ldots, t_{N+1}$ are stored in the array capt() (see tables 2 and 3 ). The first rainfall period begins at time $t_{1}$ and ends at time $t_{2}$; the $i^{\text {th }}$ rainfall period begins at time $t_{i}$ and ends at time $t_{i+1}$. Rainfall intensities for each period are stored either in the array cri(), if constant over the study area, or in the files rifil(1), .., rifil(nper) if intensity during each period varies over the study area (table 2 ). 


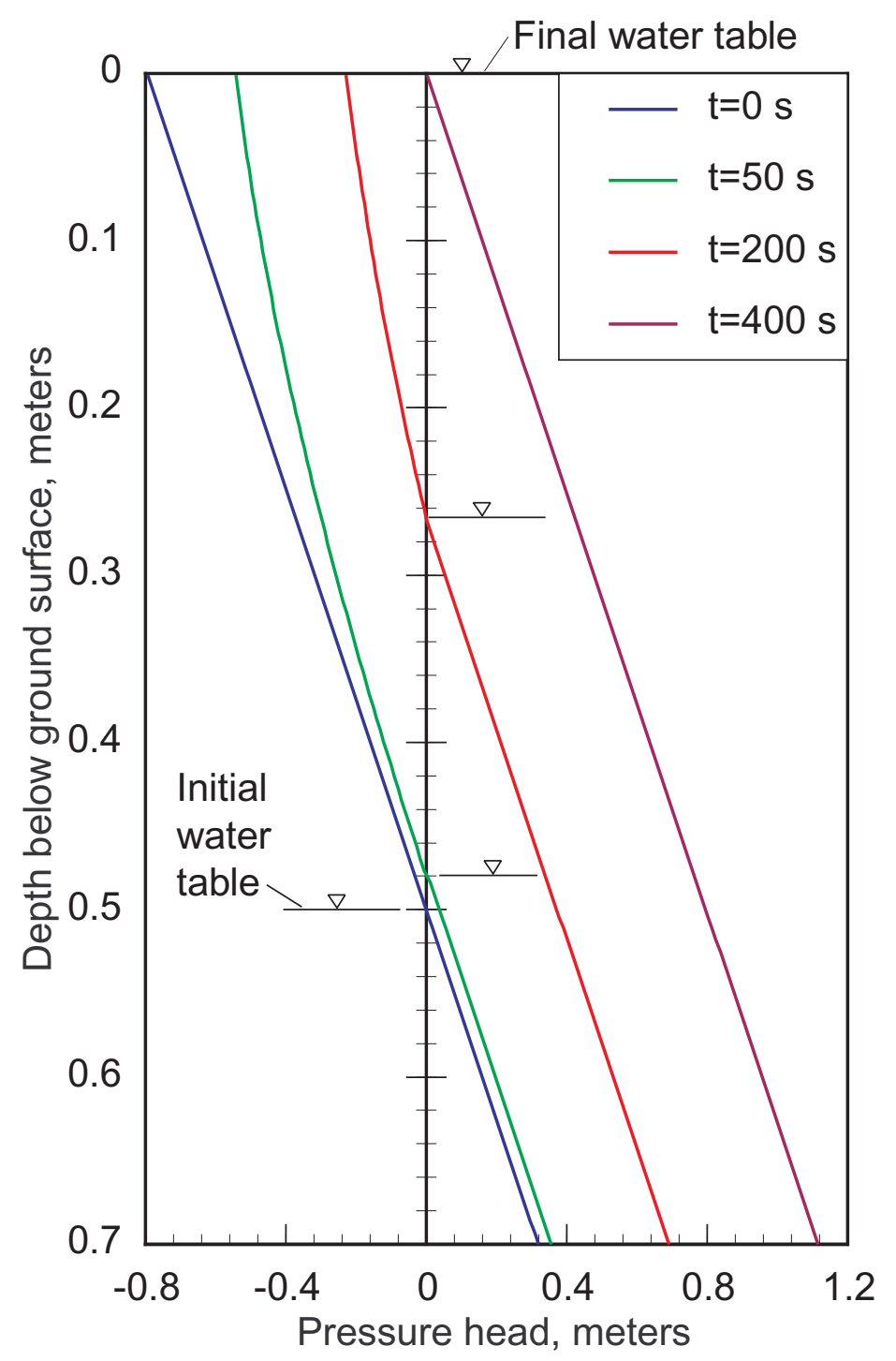

Figure 5. Example of transient water-table rise and pressure-head changes in response to precipitation at cell where steady upward flow occurs but the water table is initially beneath the ground surface. TRIGRS maintains the initial upward hydraulic gradient below the water table and adds the transient infiltration solution to the initial condition above the water table. In the example shown here, Ks=1.e- $4 \mathrm{~m} / \mathrm{s}$, Diffusivity $=1 . e-3 \mathrm{~m}^{2} / \mathrm{s}$, slope $=31^{\circ}$, initial flux $=-1.0 \mathrm{e}-5$, precipitation rate $5 . \mathrm{e}-5 \mathrm{~m} / \mathrm{s}$. 


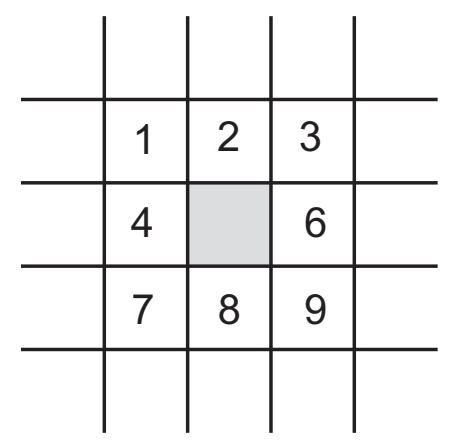

Topolndex direction codes

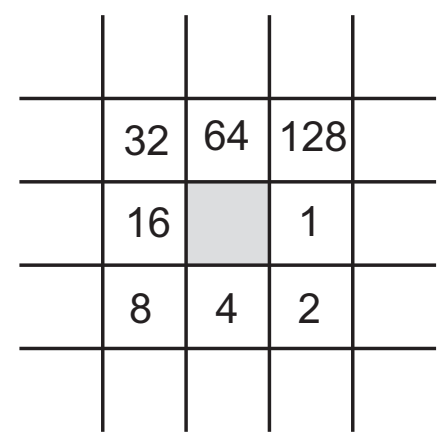

ESRI direction codes

Figure 6. Diagram comparing numeric codes for D8 flow directions used by the utility program TopoIndex with that used by ESRI Arc/Info. 


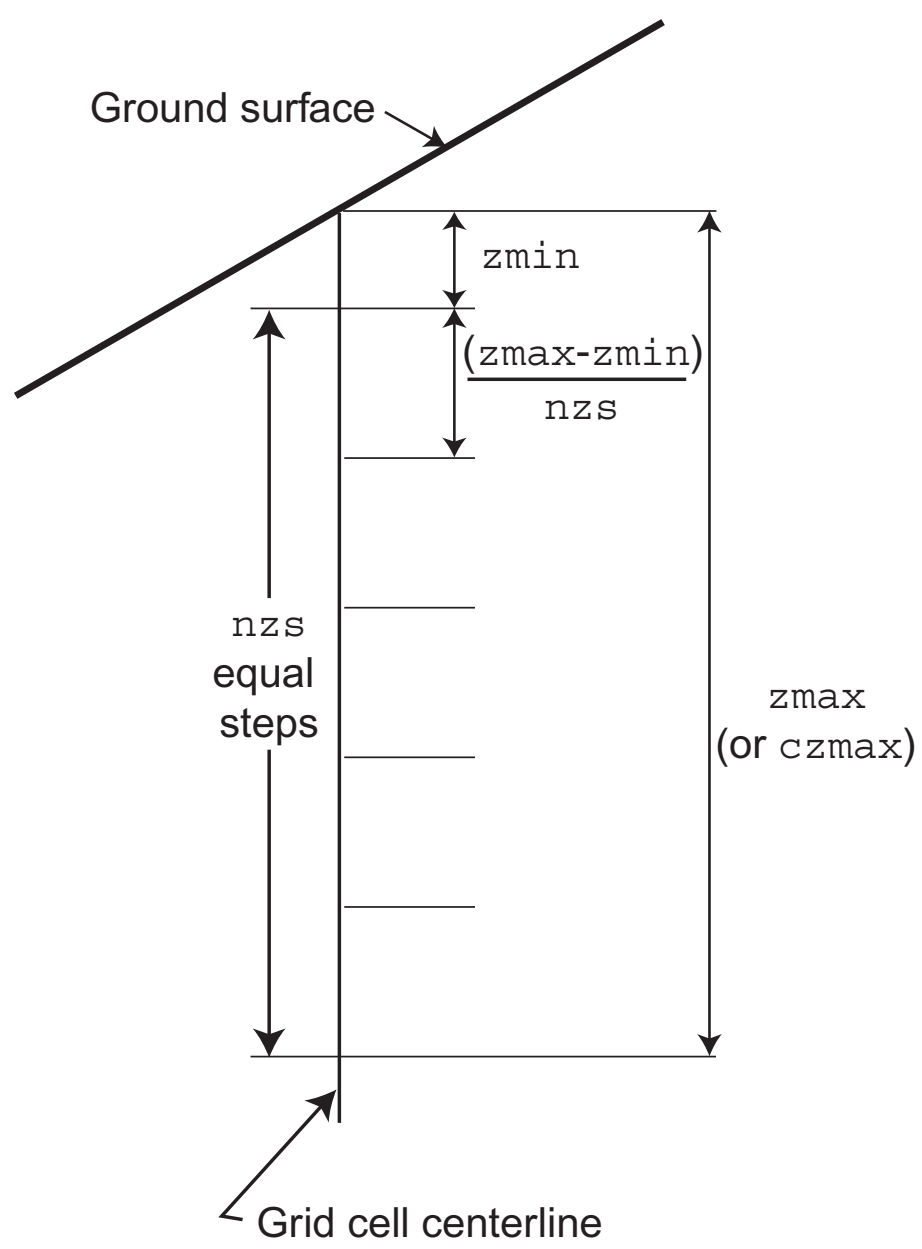

Figure 7. Vertical spacing for computing infiltration and factor of safety. The user specifies the upper limit, zmin, the lower limit, zmax, and the number of steps, nzs, (table 3). To prevent division by zero, the upper limit, zmin, should be a small, finite depth below the ground surface. TRIGRS will compute the pore pressure and factor of safety at equally spaced depths between zmin and zmax. 


\begin{tabular}{|c|c|c|c|c|c|}
\hline 1 & 2 & 3 & 4 & 5 & 6 \\
\hline 7 & 8 & 9 & 10 & 11 & \\
\hline 12 & 13 & 14 & & 15 & 19 \\
\hline 16 & & 17 & & 18 & \\
\hline
\end{tabular}

Figure 8. TRIGRS grid cell numbering scheme.

Numbering begins at upper left (northwest) corner of a grid and increases from left to right, row by row. No-data cells (shaded) are not numbered. 


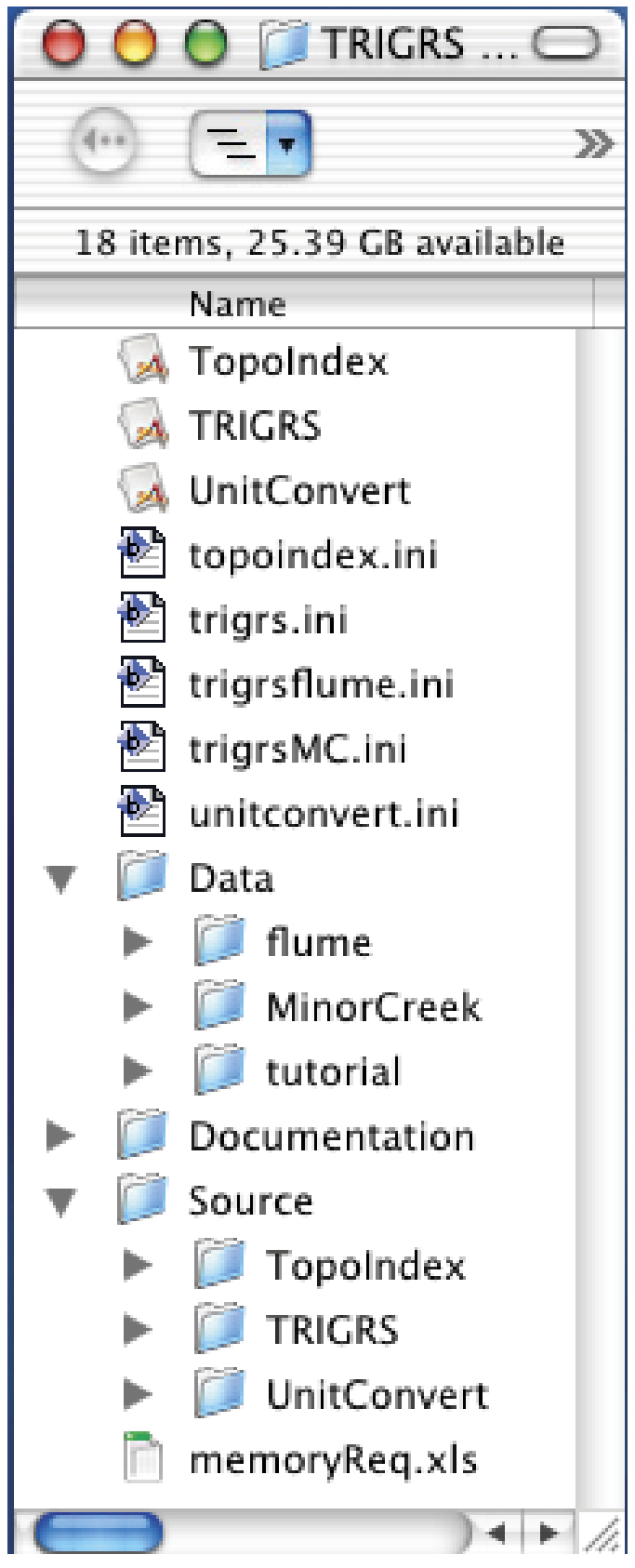

Figure B1. Screen image, showing contents of the TRIGRS folder and sub folders. 


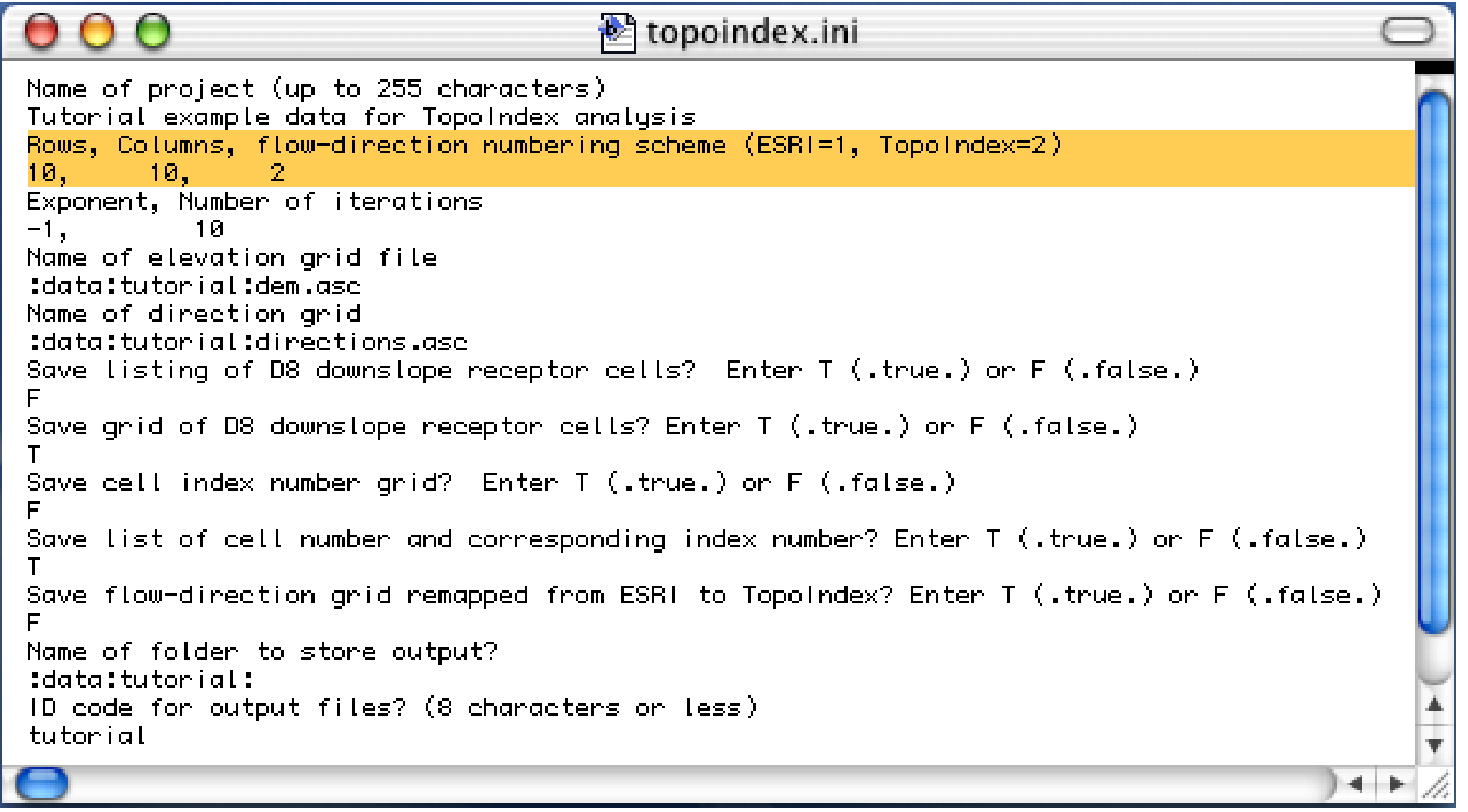

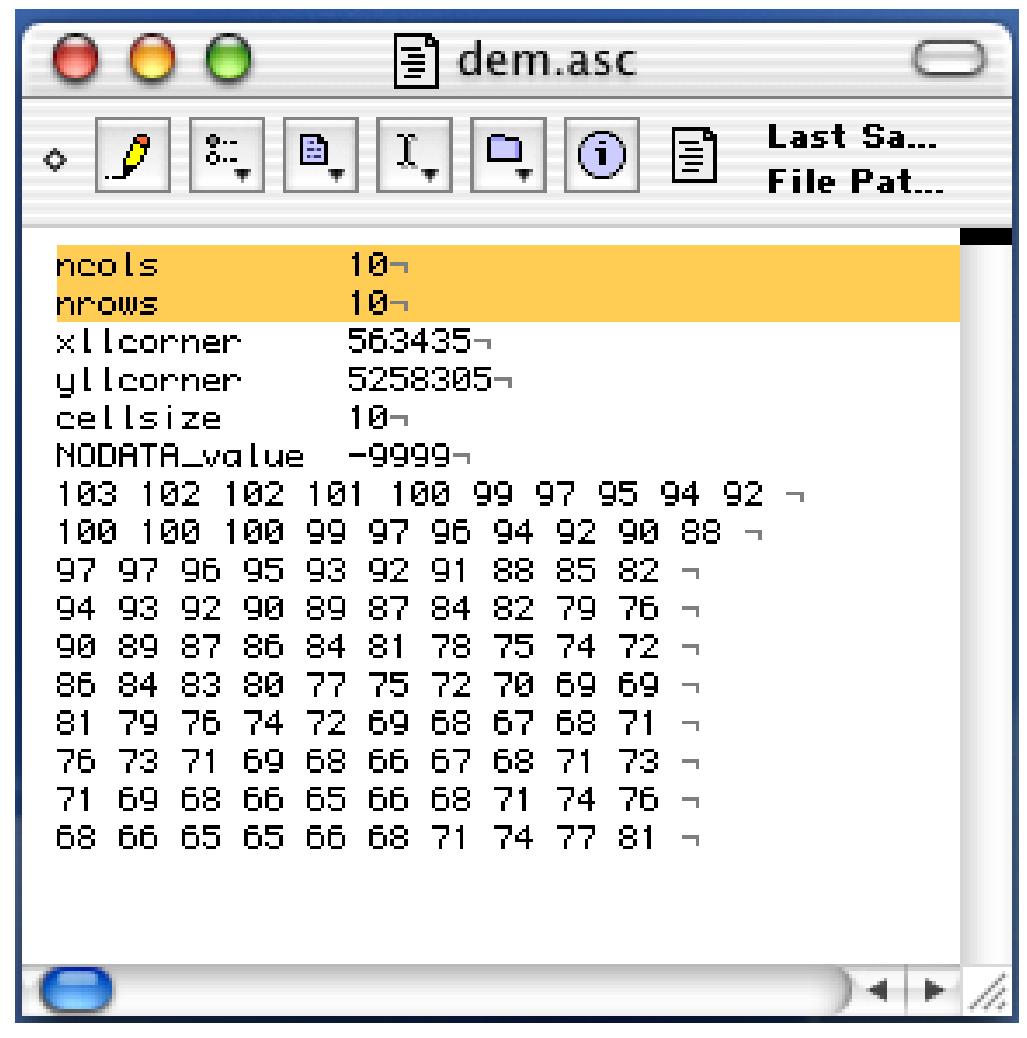

Figure B2. Screen images of the files "topoindex.ini" and "dem.asc" with grid dimensions highlighted. 


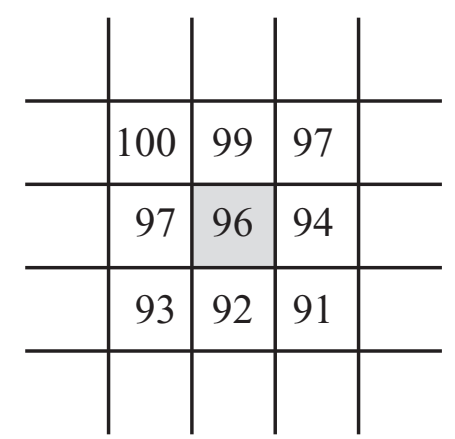

Grid cell elevation

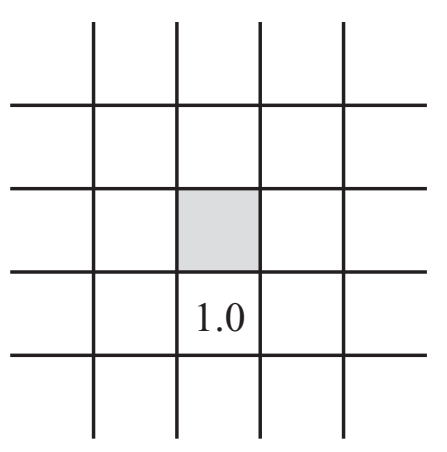

D8 weighting factor

(exponent $>20$ )

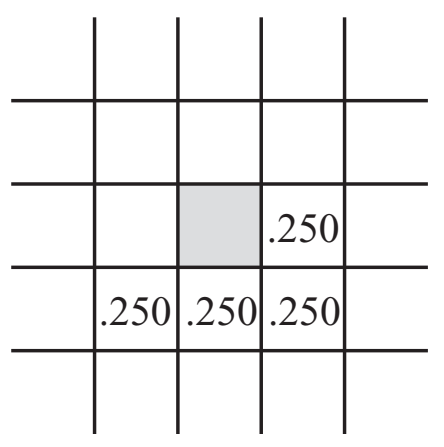

uniform weighting factor (exponent $=0$ )

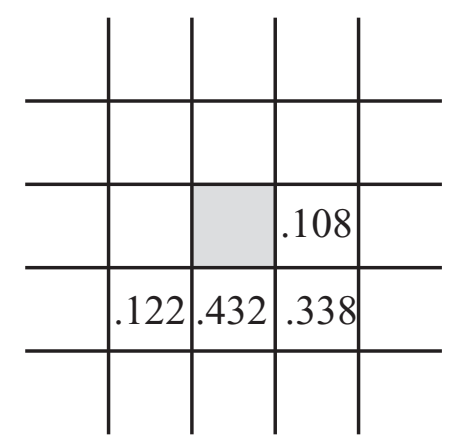

slope squared weighting factor (exponent $=2$ )

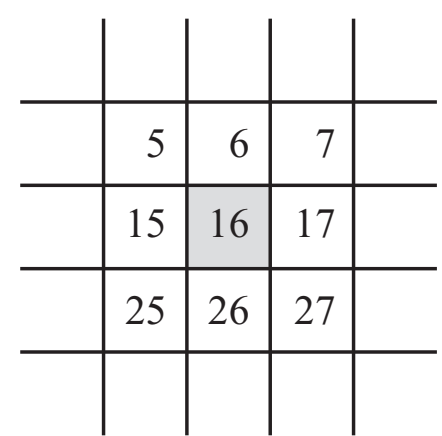

Grid cell number

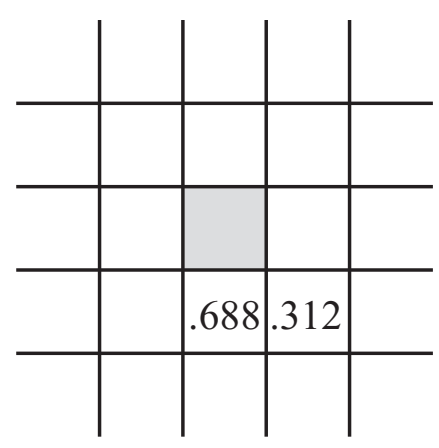

D-infinity weighting factor (exponent=-1)

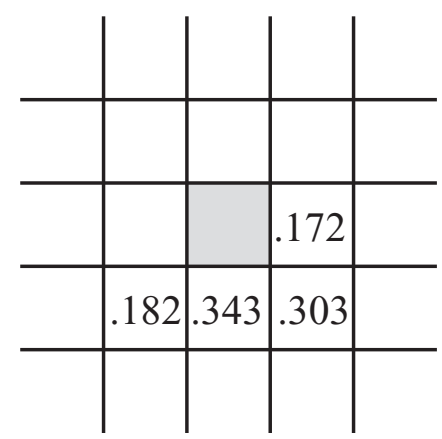

Figure B3. Example weighting factors for runoff distribution from an arbitrary cell (\#16 of the tutorial grid file). $A$. Elevation at cell 16 (shaded) and its nearest neighbor cells. B. Grid cell numbers. C. Weighting factor for D8 method. $D$. Weighting factors for the Dinfinity method. $E$., ..., $\mathrm{H}$. Slope power-law weighting factors for various exponents. Note that weighting factors of flatter cells approach zero as the exponent increases. $E$. Uniform distribution to all adjacent downslope cells. F. Distribution to all adjacent downslope cells, weighting factor proportional to slope. $G$. Distribution to adjacent downslope cells, weighting factor proportional to square of slope. $\mathrm{H}$. Distribution to adjacent downslope cells, weighting factor proportional to slope raised to $20^{\text {th }}$ power.

Weighting factors for cells 17 and 25 are zero slope proportional weighting factor (exponent $=1$ )

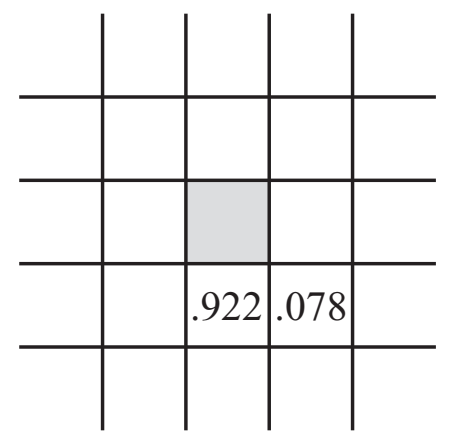

power-law weighting factor (exponent=20) 


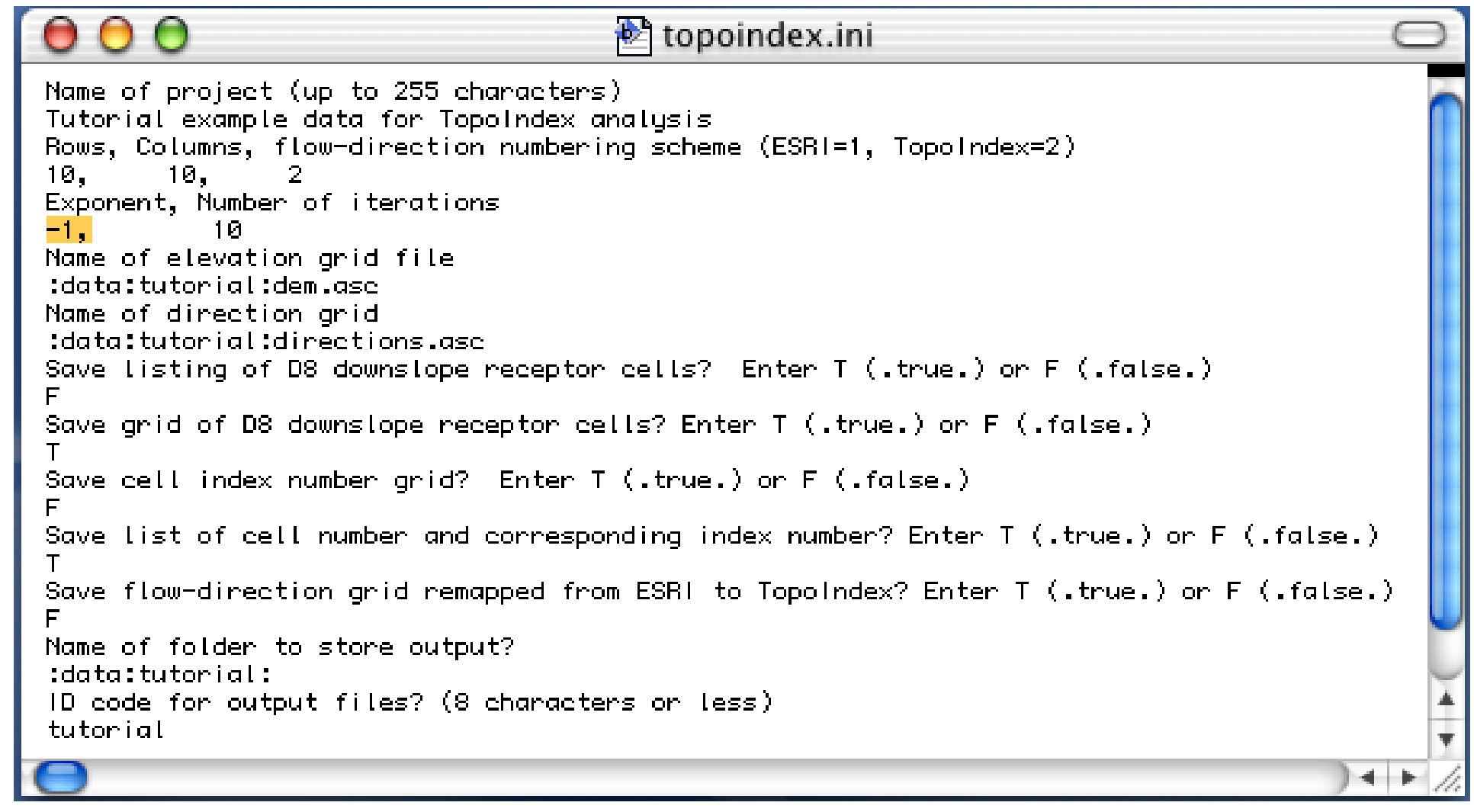

Figure B4. Screen image of the file "topoindex.ini" with value of exponent, $\omega$, highlighted. 


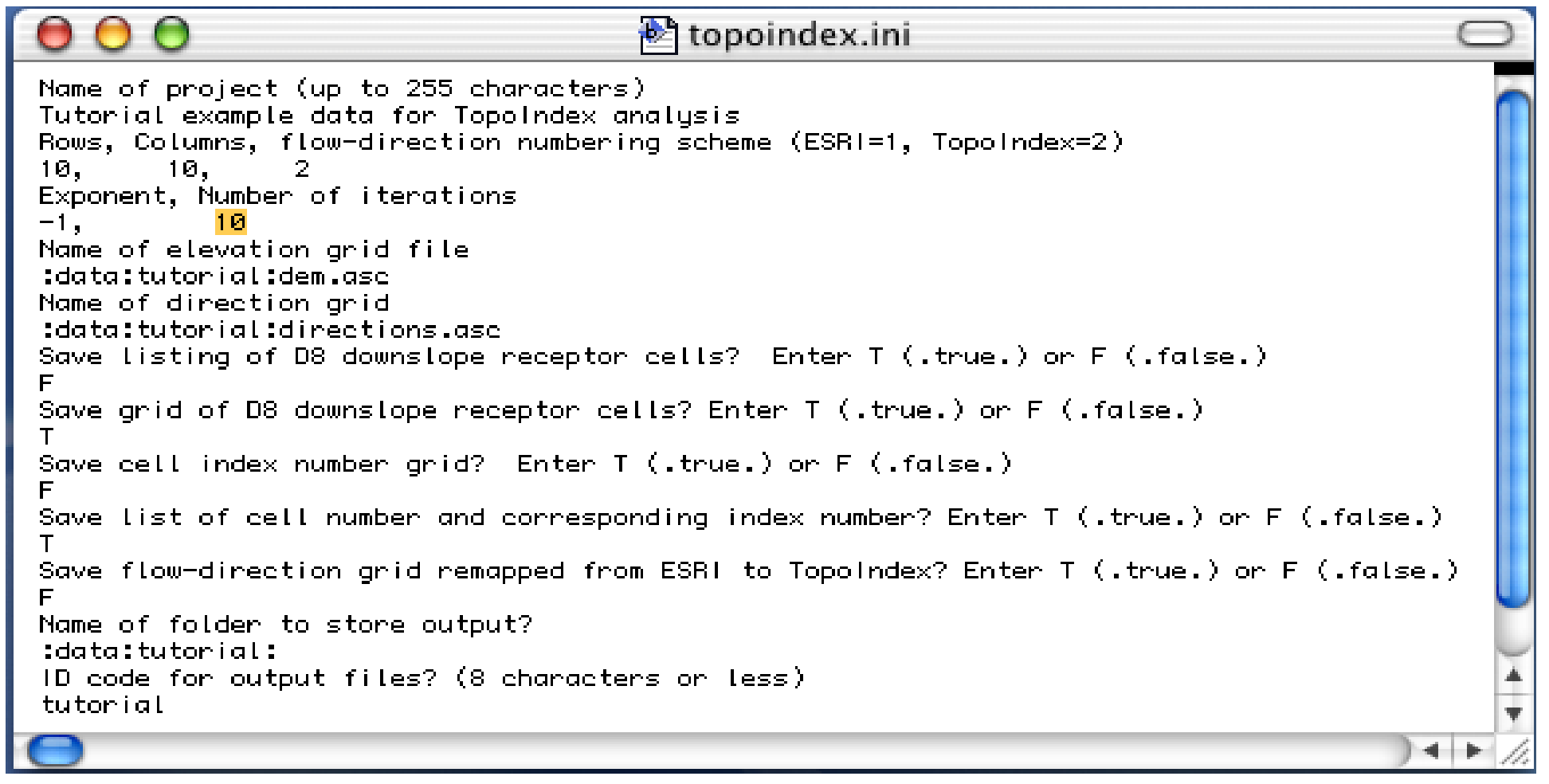

Figure B5. Screen image of the file "topoindex.ini" with maximum number of iterations highlighted. 


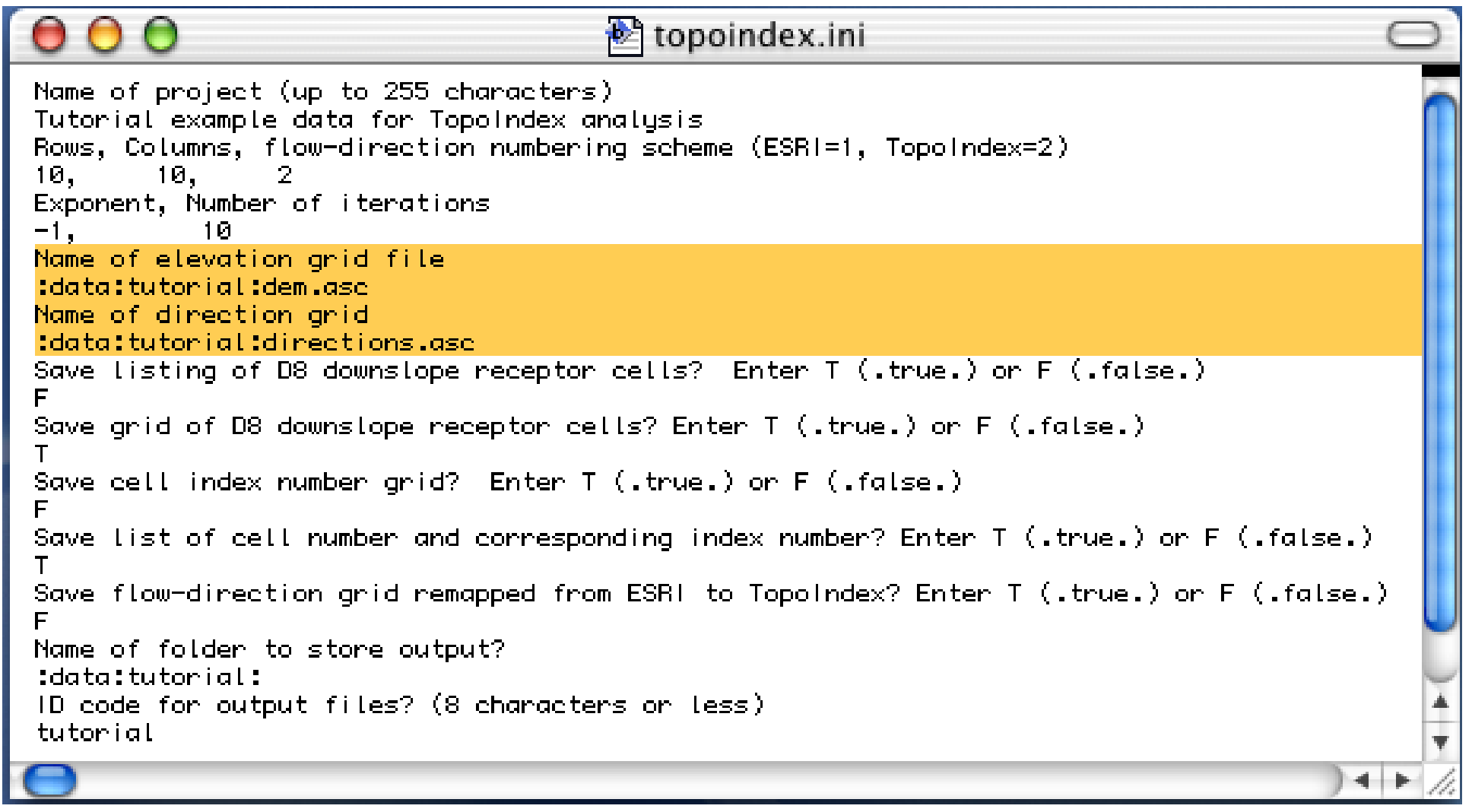

Figure B6. Screen image of the file "topoindex.ini" with lines containing names of input files highlighted. 


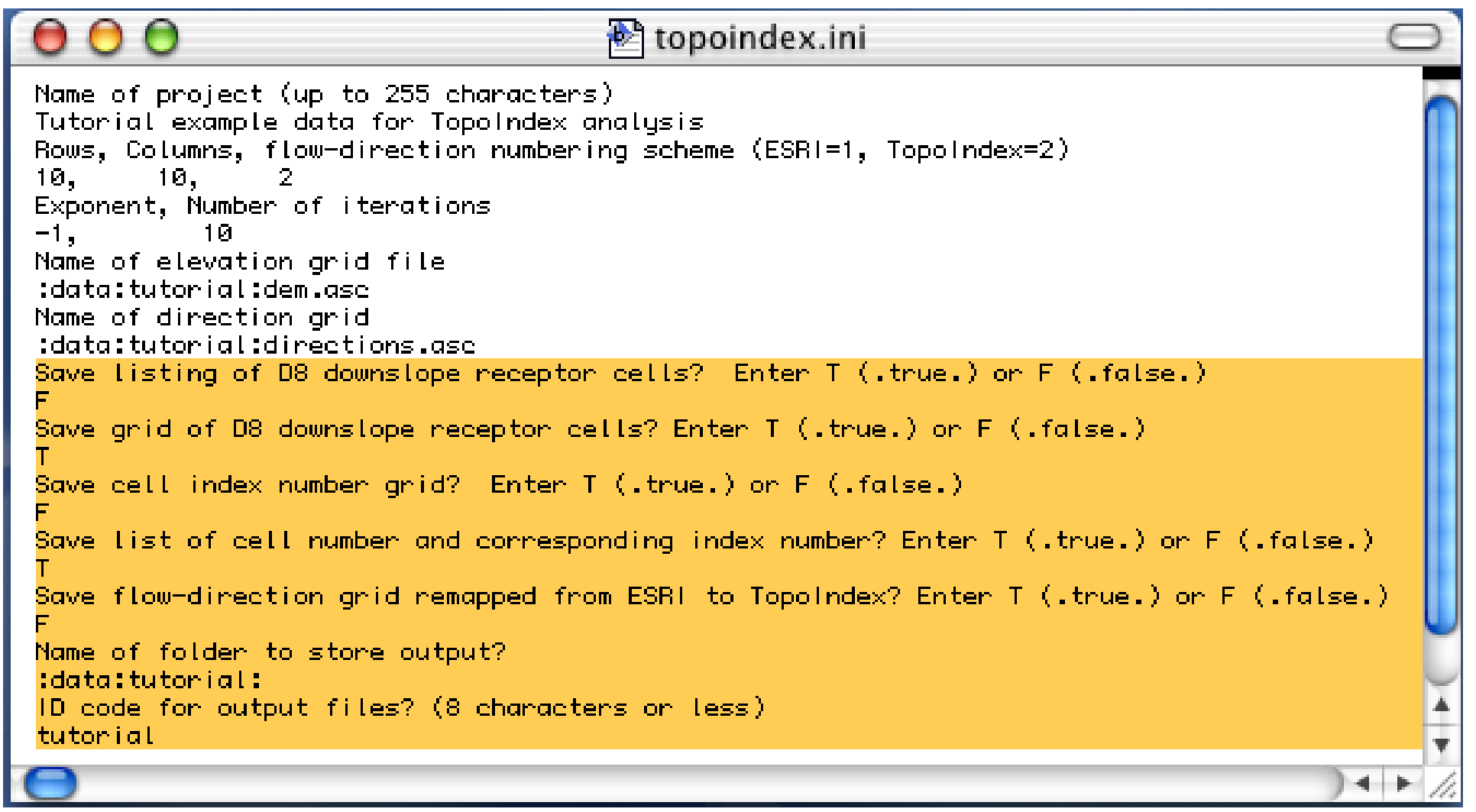

Figure B7. Screen image of the file "topoindex.ini" with lines for selecting output files highlighted. 


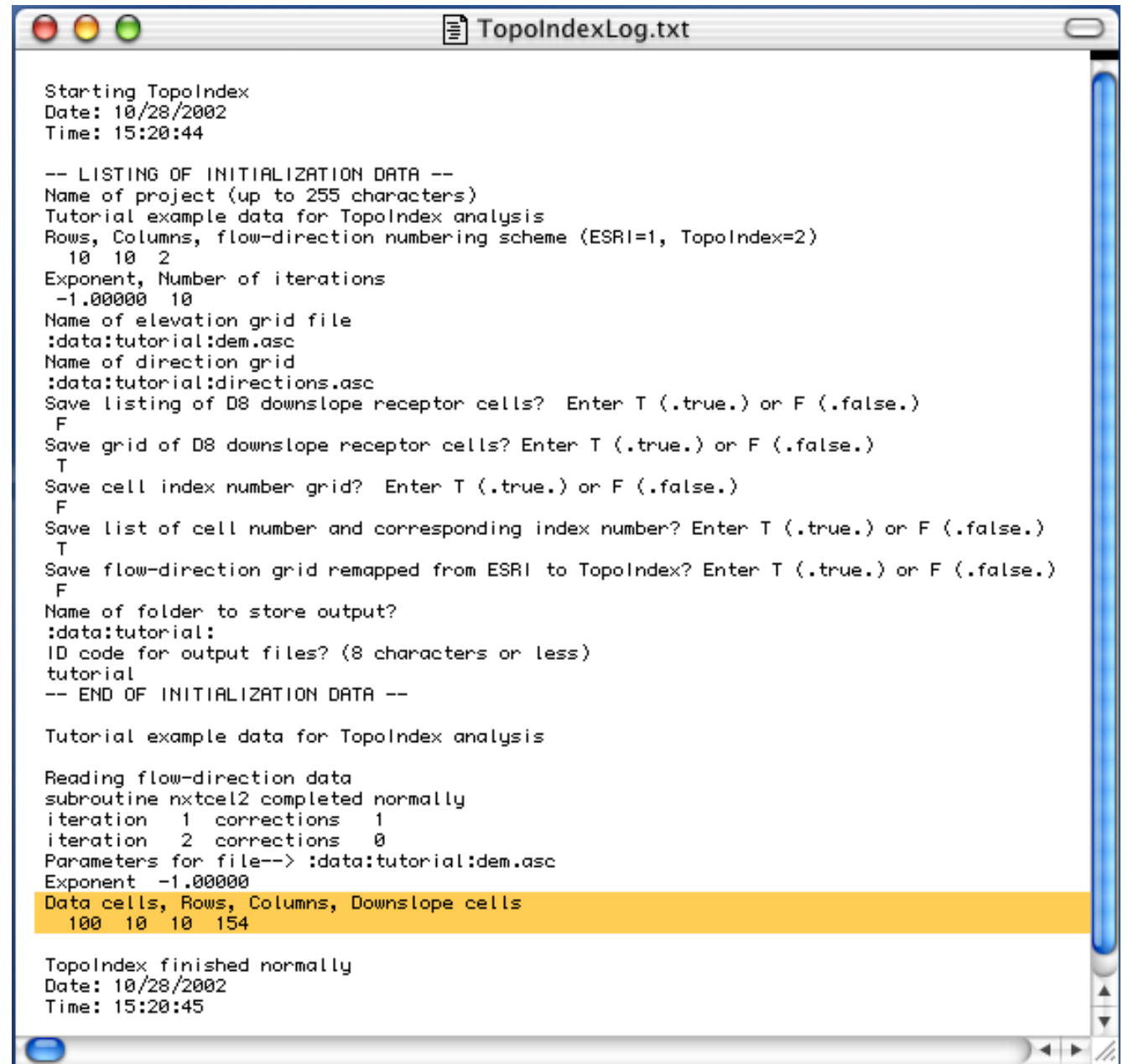

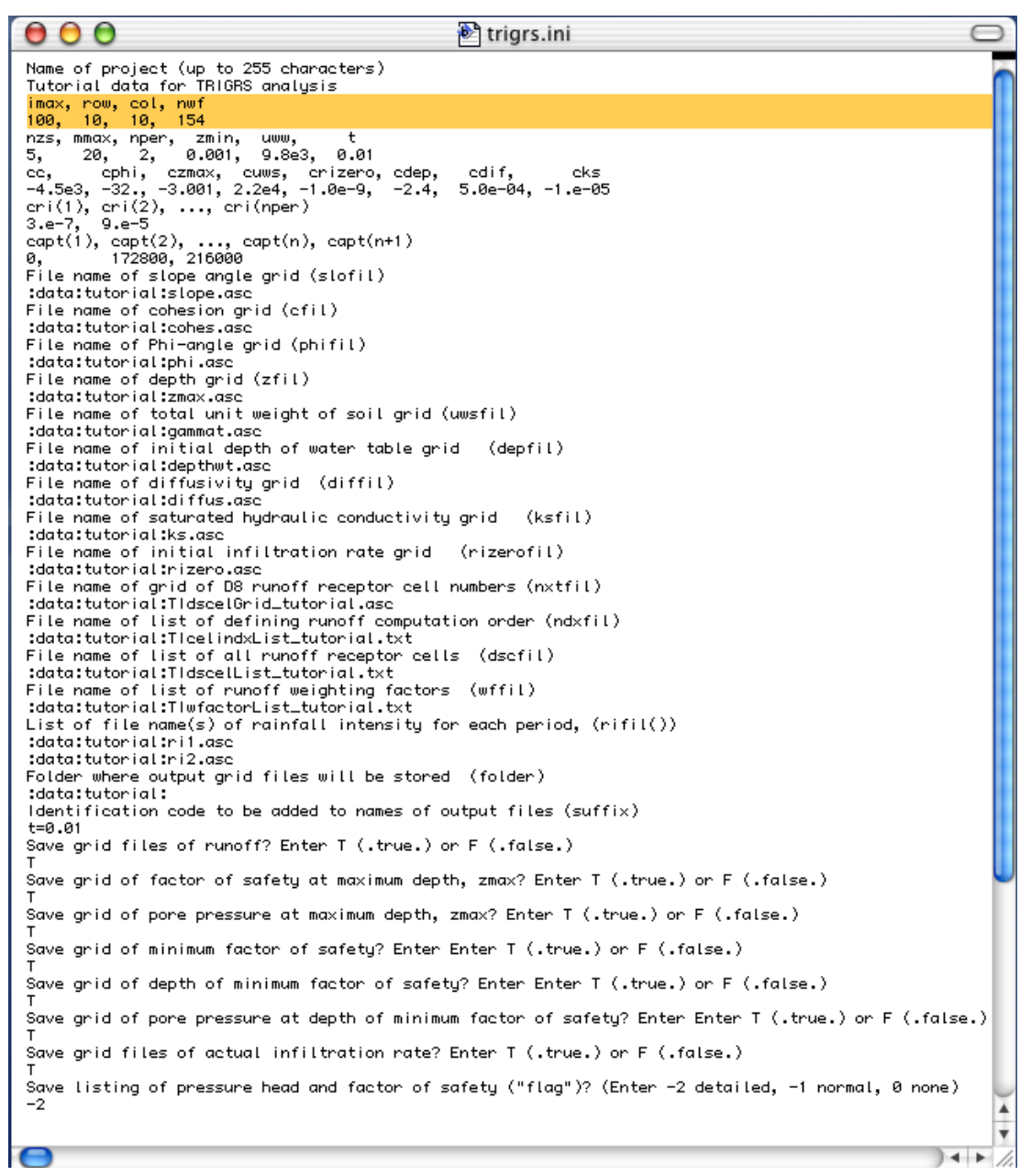

Figure B8. Screen images of the file "trigrs.ini" and "TopolndexLog.txt" with array length parameters highlighted. 


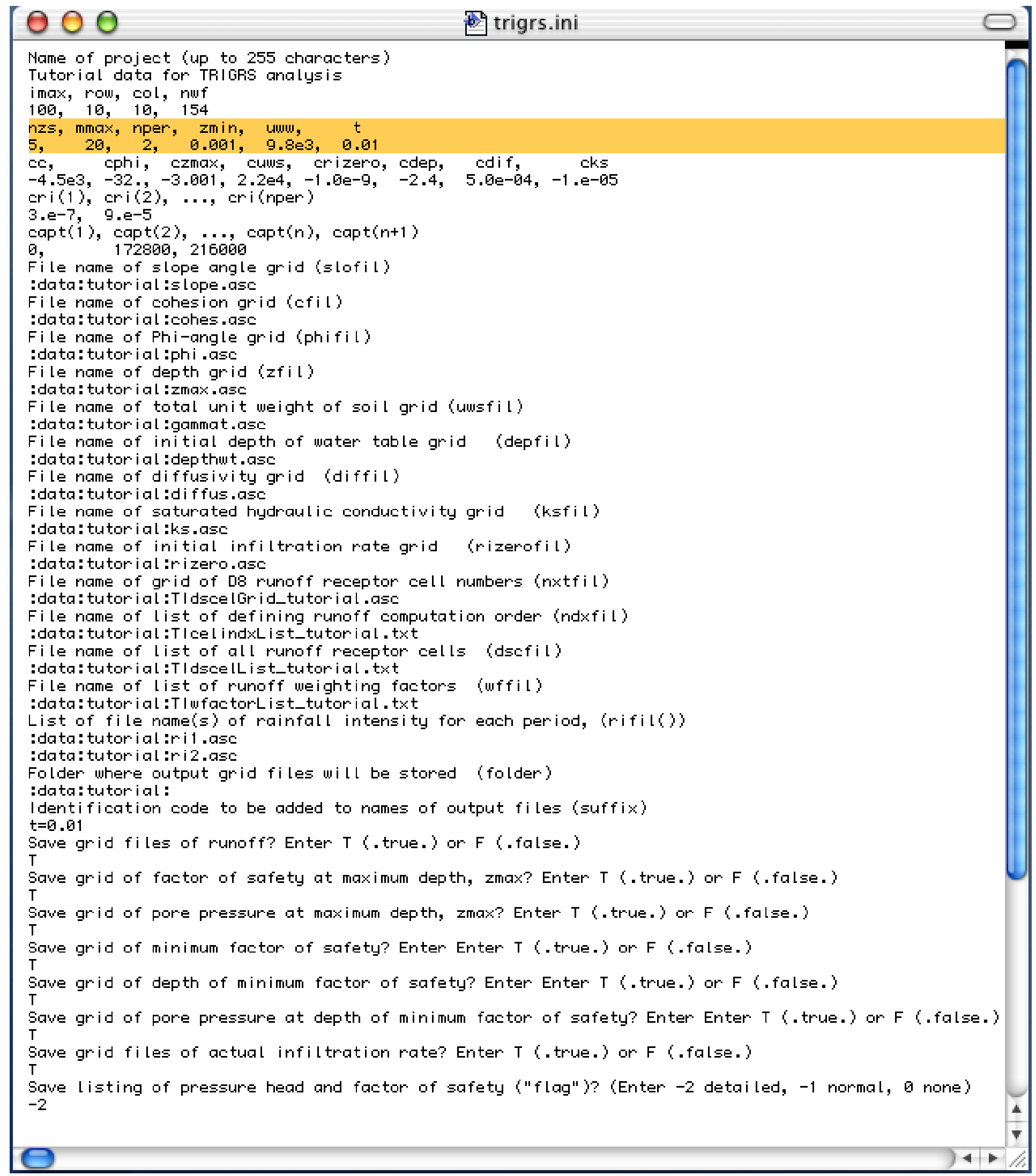

Figure B9. Screen image of the file "trigrs.ini" with parameters that control a given simulation highlighted. 


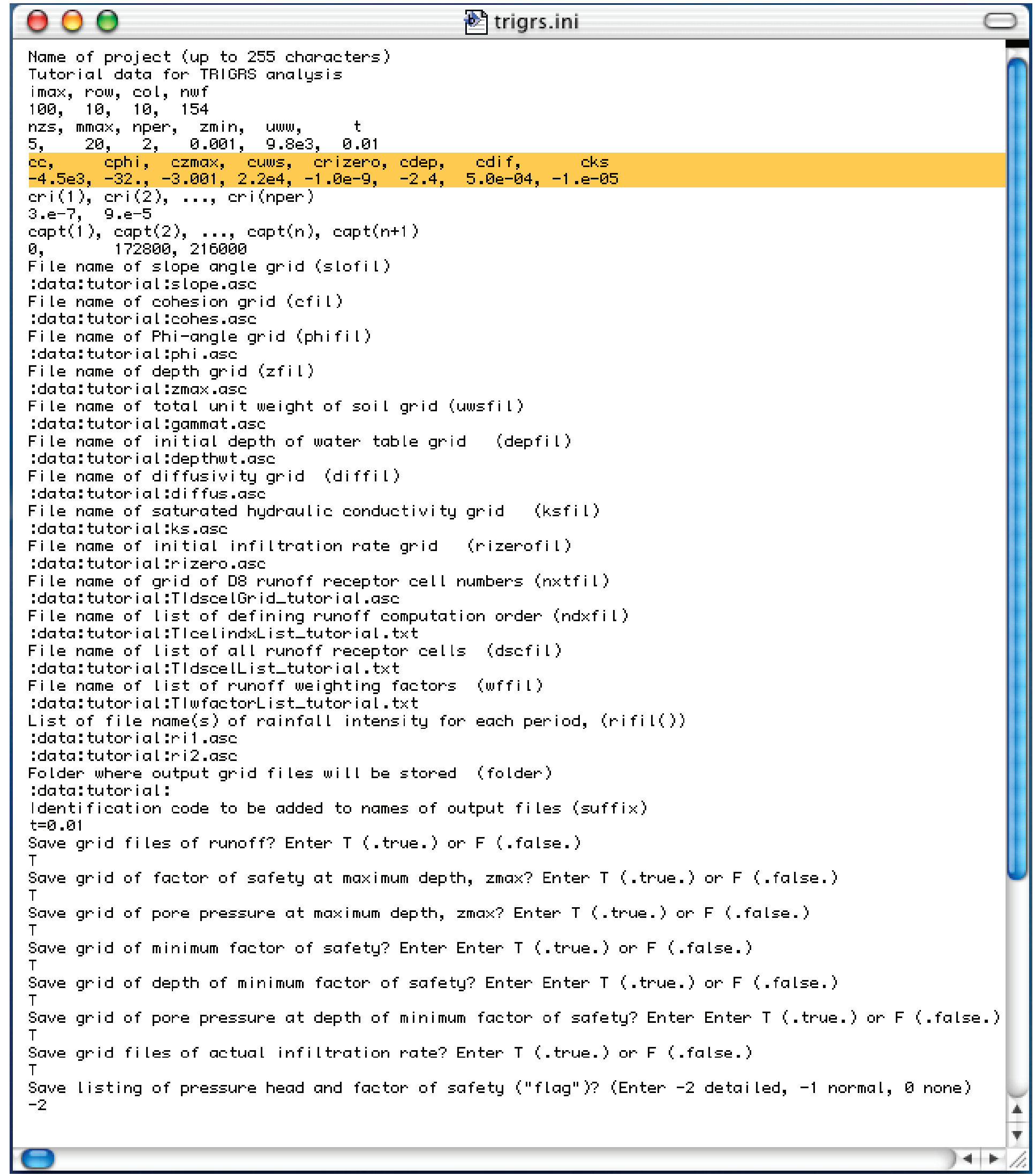

Figure B10. Screen image of the file "trigrs.ini" with physical parameters highlighted. 


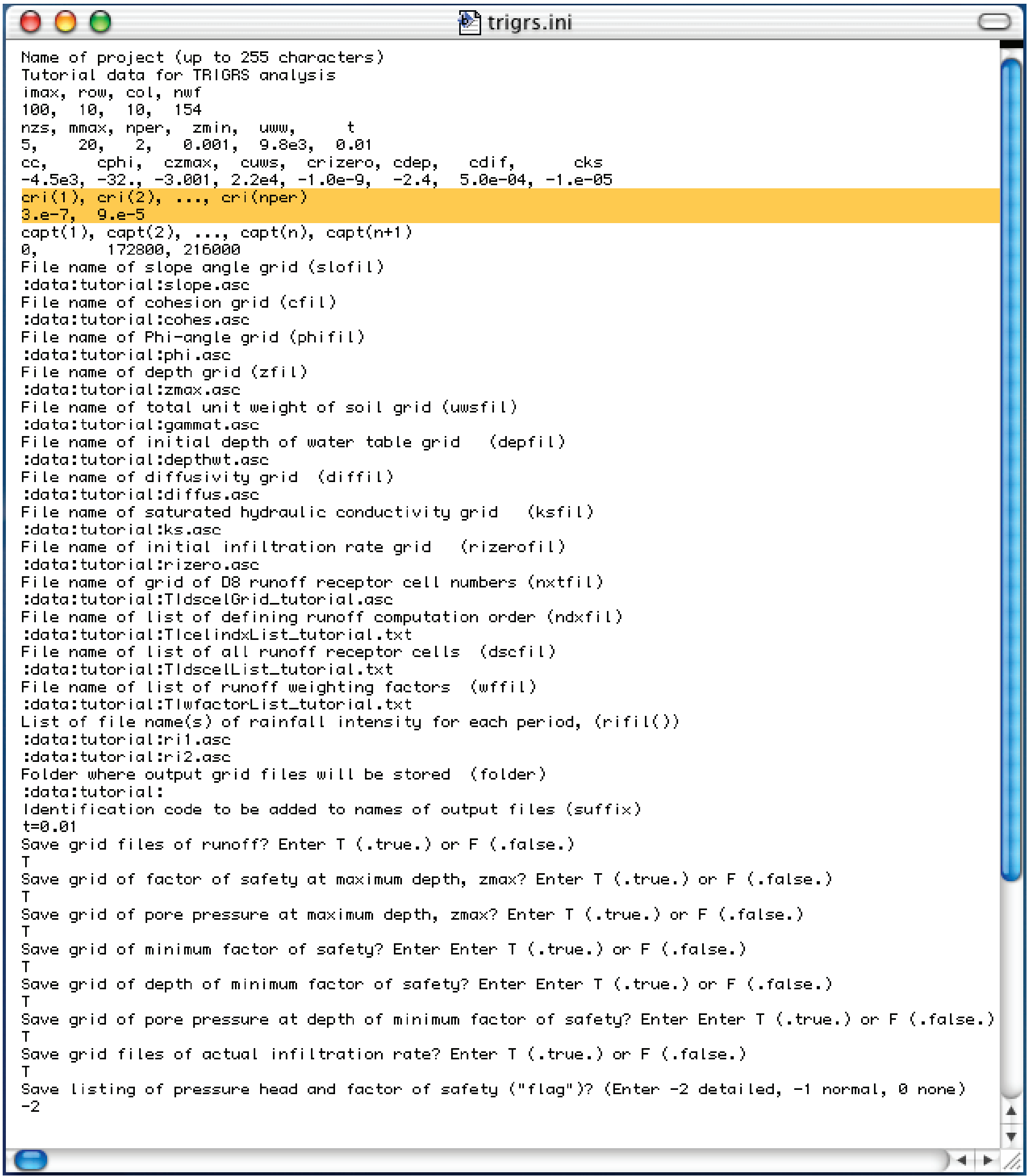

Figure B11. Screen image of the file "trigrs.ini" with rainfall intensities, $I_{n z}$, highlighted. 


\begin{tabular}{|c|}
\hline 000 trigrs.ini \\
\hline 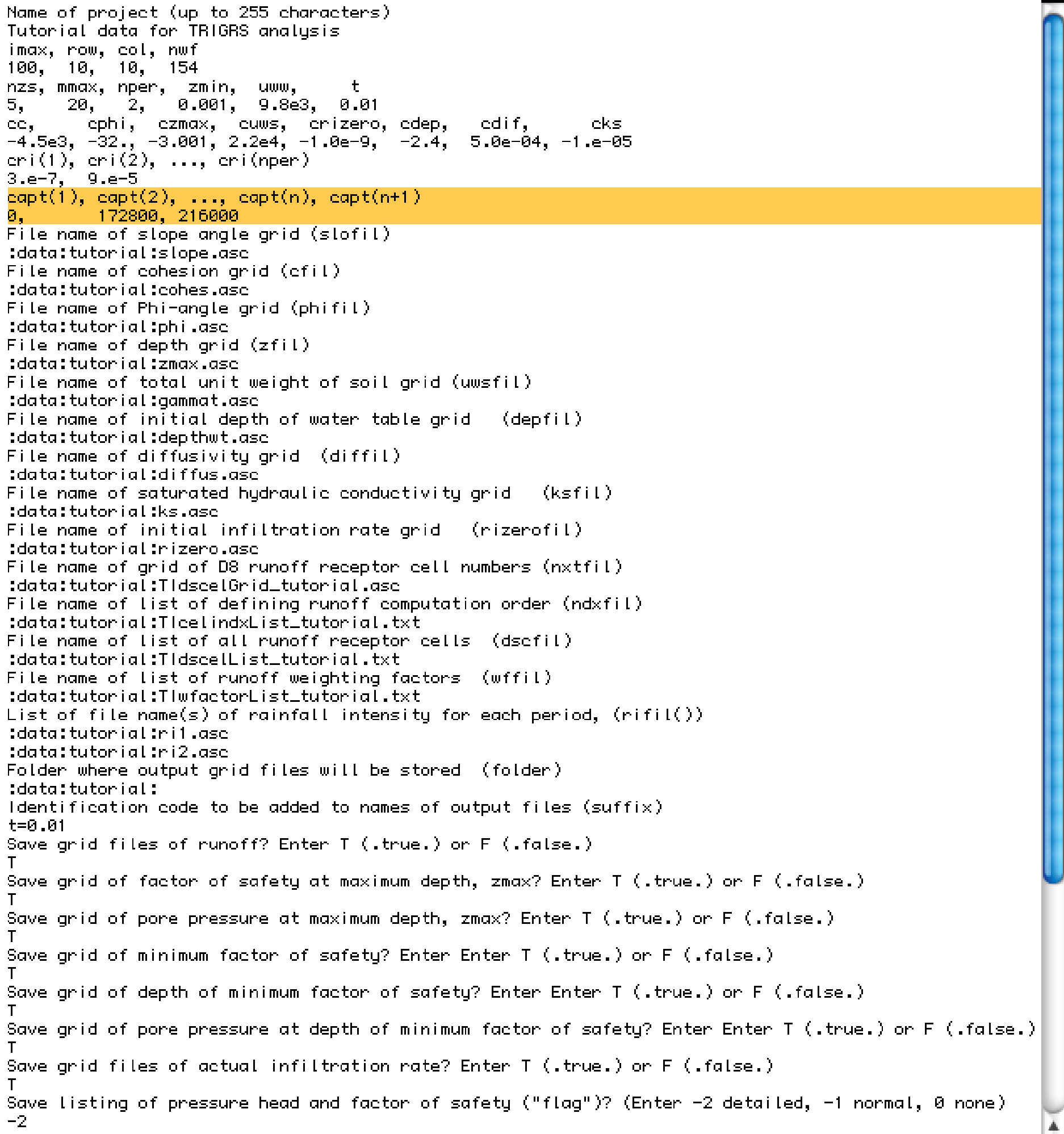 \\
\hline
\end{tabular}

Figure B12. Screen image of the file "trigrs.ini" with times that define the beginning and ending of successive rainfall periods, $t_{n}$, highlighted. 


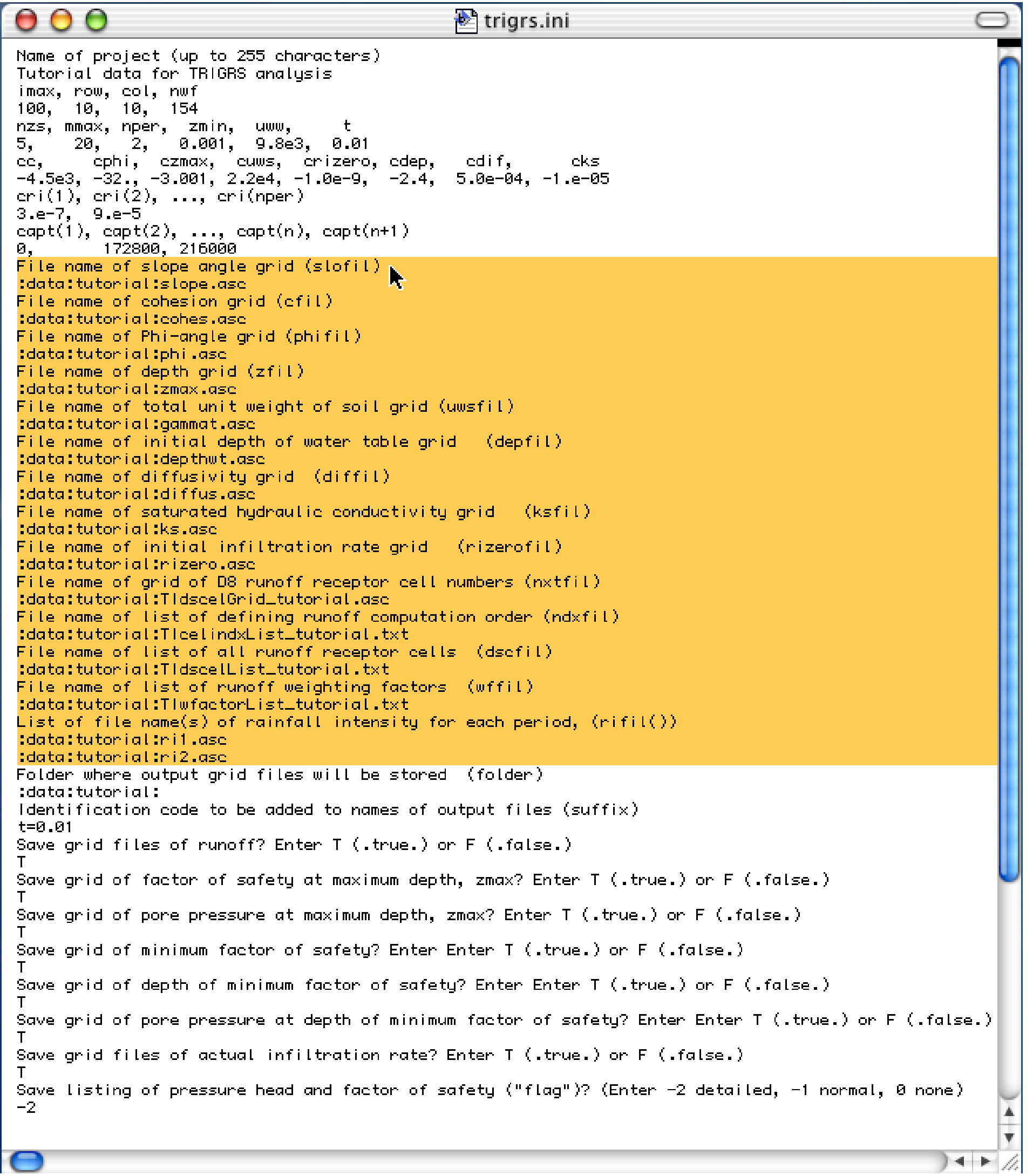

Figure B13. Screen image of the file "trigrs.ini" with lines that list input files highlighted. An arrow pointer appears next to the name of the mandatory input grid file of slope angles. 
Name of project (up to 255 characters)

Tutorial data for TRIGRS analysis

imax, row, col, nuf

$100,10,10,154$

nzs, mmax, nper, zmin, uww, t

$5, \quad 20,2, \quad 0.001, \quad 9.8 \mathrm{e} 3, \quad 0.01$

cc, cphi, czmax, cuws, crizero, cdep, cdif, cks

$4.5 e 3,-32 .,-3.001,2.2 \mathrm{e} 4,-1.0 \mathrm{e}-9,-2.4,5.0 \mathrm{e}-04,-1 . e-05$

cri(1), cri(2), .., cri (nper)

3.e-7, $9 . e^{-5}$

$\operatorname{capt}(1), \operatorname{capt}(2), \ldots, \operatorname{capt}(n), \operatorname{capt}(n+1)$

a, 172800,216000

File name of slope angle grid (slofil)

:data: tutorial:slope.asc

File name of cohesion grid (cfil)

none

File name of Phi-angle grid (phifil)

:data: tutorial:phi .asc

File name of depth grid ( $\mathrm{zfil}$ )

:data: tutorial:zmax.asc

File name of total unit weight of soil grid (uwsfil)

:data: tutorial :gammat.asc

File name of initial depth of water table grid (depfil)

:data: tutorial :dep thw t.asc

File name of diffusivity grid (diffil)

:data: tutorial:diffus.asc

File name of saturated hydraulic conductivity grid (ksfil)

:data: tutorial:ks.asc

File name of initial infiltration rate grid (rizerofil)

:data: tutorial:rizero.asc

File name of grid of $D 8$ runoff receptor cell numbers (nxtfil)

:data: tutorial:TIdscelGrid_tutorial .asc

File name of list of defining runoff computation order (ndx fil)

:data: tutorial: TIcel indxList_tutorial . txt

File name of list of all runoff receptor cells (dscfil)

:data: tutorial:TIdscellist_tutorial . txt

File name of list of runoff weighting factors (wffil)

:data: tutorial:TI wfactorList_tutorial . txt

List of file name(s) of rainfall intensity for each period, (rifil())

:data: tutorial:ri1.asc

:data: tutorial:ri2.asc

Folder where output grid files will be stored (folder)

:data: tutorial:

Identification code to be added to names of output files (suffix)

$\mathrm{t}=0.01$

Save grid files of runoff? Enter T (.true.) or F (.false.)

$\mathrm{T}$

Save grid of factor of safety at maximum depth, zmax? Enter T (.true.) or F (.false.)

$\mathrm{T}$

Save grid of pore pressure at maximum depth, zmax? Enter T (.true.) or F (.false.)

$\mathrm{T}$

Save grid of minimum factor of safety? Enter Enter T (.true.) or F (.false.)

$\mathrm{T}$

Save grid of depth of minimum factor of safety? Enter Enter T (.true.) or F (.false.)

$\mathrm{T}$

Save grid of pore pressure at depth of minimum factor of safety? Enter Enter T (.true.) or F (.false.)

T

Save grid files of actual infiltration rate? Enter T (.true.) or F (.false.)

T

Save listing of pressure head and factor of safety ("flag")? (Enter -2 detailed, -1 normal, 0 none)

$-2$

Figure B14. Screen image of the file "trigrs.ini" with example placeholder for the name of a non-existent file highlighted. 
Name of project (up to 255 characters)

Tutorial data for TRIGRS analysis

imax, row, col, nwf

$100,10,10,154$

nzs, mmax, nper, zmin, uww, t

$5, \quad 20,2, \quad 0.001,9.8 \mathrm{e}, \quad 0.01$

cc, cphi, czmax, cuws, crizero, cdep, cdif, cks

$4.5 e 3,-32 .,-3.001,2.2 e 4,-1.0 e-9,-2.4,5.0 e-04,-1 . e-05$

cri $(1)$, cri $(2), \ldots$, cri (nper)

3.e-7, $9 . e-5$

$\operatorname{capt}(1), \operatorname{capt}(2), \ldots, \operatorname{capt}(n), \operatorname{capt}(n+1)$

a, 172800, 216000

File name of slope angle grid (slofil)

:data: tutorial:slope.asc

File name of cohesion grid (cfil)

:data: tutorial :cohes.asc

File name of Phi-angle grid (phifil)

:data: tutorial:phi .asc

File name of depth grid ( $\mathrm{zfil}$ )

:data: tutorial:zmax.asc

File name of total unit weight of soil grid (uwsfil)

:data: tutorial:gammat.asc

File name of initial depth of water table grid (depfil)

:data: tutorial :depthwt.asc

File name of diffusivity grid (diffil)

:data: tutorial:diffus.ase

File name of saturated hydraulic conductivity grid (ksfil)

:data: tutorial:ks.asc

File name of initial infiltration rate grid (rizerofil)

:data: tutorial:rizero.asc

File name of grid of 08 runoff receptor cell numbers (nxtfil)

:data: tutorial:TIdscelGrid_tutorial .asc

File name of list of defining runoff computation order (ndx $f i l$ )

:data: tutorial:Tlcel indxList_tutorial .txt

File name of list of all runoff receptor cells (dscfil)

:data: tutorial:TIdscelList_tutorial.txt

File name of list of runoff weighting factors (wffil)

:data: tutorial:TI wactorList_tutorial .txt

List of $f i l e$ name(s) of rainfall intensity for each period, (rifil( )

:data: tutorial:ri1 .asc

:data: tutorial:ri2.asc

Folder where output grid files will be stored (folder)

:data: tutorial:

Identification code to be added to names of output files (suffix)

$t=0.01$

Save grid files of runoff? Enter T (.true.) or F (.false.)

T

Save grid of factor of safety at maximum depth, zmax? Enter T (.true.) or F (.false.)

T

Save grid of pore pressure at maximum depth, zmax? Enter T (.true.) or F (.false.)

T

Save grid of minimum factor of safety? Enter Enter T (.true.) or F (.false.)

T

Save grid of depth of minimum factor of safety? Enter Enter T (.true.) or F (.false.)

T

Save grid of pore pressure at depth of minimum factor of safety? Enter Enter T (.true.) or F (.false.)

$T$

Save grid files of actual infiltration rate? Enter T (.true.) or F (.false.)

T

Save listing of pressure head and factor of safety ("flag")? (Enter -2 detailed, -1 normal, 0 none)

$-2$

Figure B15. Screen image of the file "trigrs.ini" with lines for controlling output highlighted. 


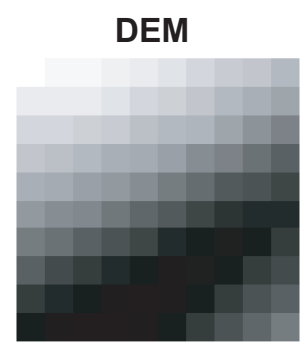

65

$103 m$

PHI

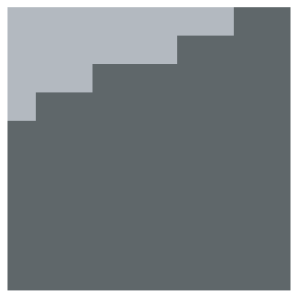

$\square \quad \square$

RUNOFF 1

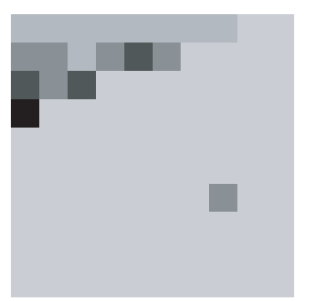

$\square \square \square \square$

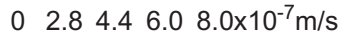

$\psi \quad \mathbf{t}=\mathbf{0 . 0 1 \mathrm { s }}$
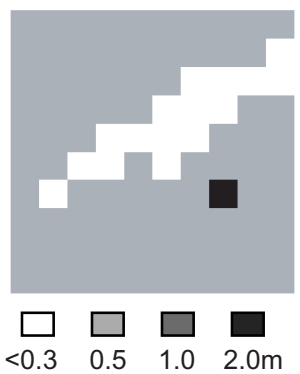

FS $t=0.01 \mathrm{~s}$

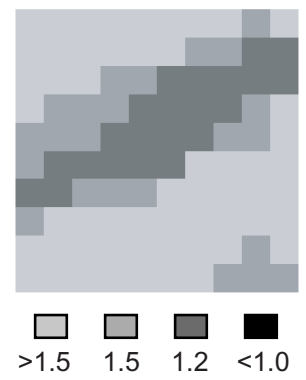

SLOPE

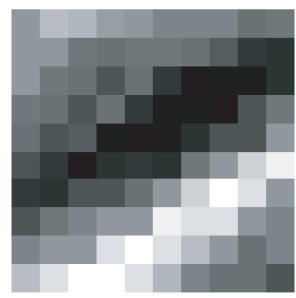

$35 \infty$
ZMAX

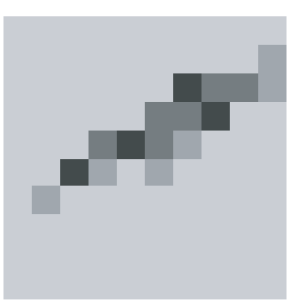

$\begin{array}{lll}\square & \square \\ 1.5 \quad & \square .75 \quad \square & \\ 2.0 \mathrm{~m}\end{array}$

$D_{s}$

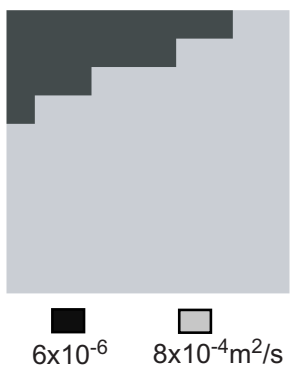

INFILTRATION 1

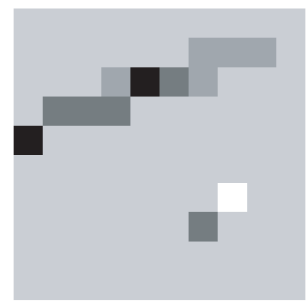

$\square \square \square \square \square$

$\begin{array}{llllll}0 & 0.3 & 0.5 & 0.7 & 1.1 \times 10^{-6} \mathrm{~m} / \mathrm{s}\end{array}$

$\psi \quad t=86400 s$

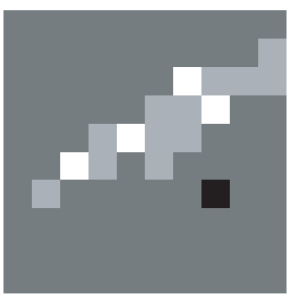

$\begin{array}{llll}\square & \square & \square & \square\end{array}$

FS $t=86400 s$

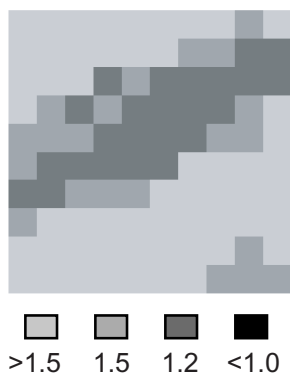

\section{COHESION}

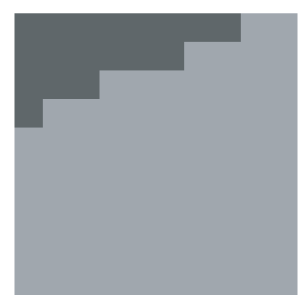

$\square .5$

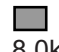

$8.0 \mathrm{kPa}$

\section{INFILTRATION 2}
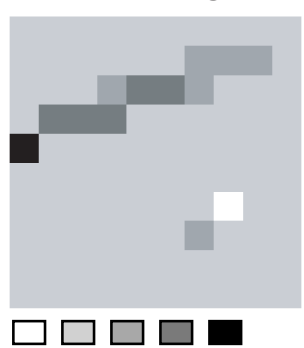

$\begin{array}{lllll}0 & 0.4 & 0.7 & 1.3 & 1.7 \times 10^{-5} \mathrm{~m} / \mathrm{s}\end{array}$

$\psi \quad t=100800 s$

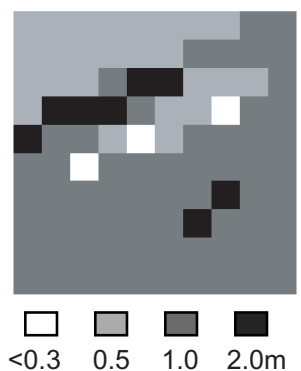

FS $t=100800 s$

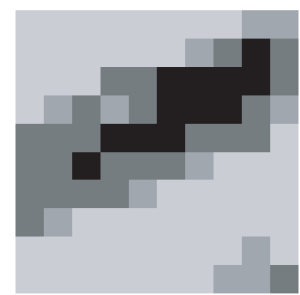

\begin{tabular}{llll}
\hline 1.5 & 1.5 & $1.2<1.0$
\end{tabular}

Figure B16. Sample analysis of data from the folder "TRIGRS:data:tutorial". The first two rows represent input data (elevation, slope angle, depth of soil, soil cohesion, internal angle of friction, hydraulic conductivity and hydraulic diffusivity). The third row shows runoff and infiltration rates during the two storm periods. The fourth row shows pressure head at the base of the soil through time and the bottom row shows the factor of safety through time. 